\title{
Human Umbilical Tissue-Derived Cells Promote Synapse Formation and Neurite Outgrowth via Thrombospondin Family Proteins
}

\author{
[DSehwon Koh, ${ }^{1}$ Namsoo Kim, ${ }^{2}$ Henry H. Yin, ${ }^{2,3,4}$ ๑Ian R. Harris, ${ }^{5}$ Nadine S. Dejneka, ${ }^{5}$ and $\mathbb{C C a g l a ~ E r o g l u ~}^{1,2,4}$ \\ Departments of ${ }^{1}$ Cell Biology, ${ }^{2}$ Neurobiology, ${ }^{3}$ Psychology and Neuroscience, and ${ }^{4}$ Duke Institute for Brain Sciences, Duke University, Durham, North \\ Carolina 27710, and 5Janssen Research and Development, Spring House, Pennsylvania 19477
}

Cell therapy demonstrates great potential for the treatment of neurological disorders. Human umbilical tissue-derived cells (hUTCs) were previously shown to have protective and regenerative effects in animal models of stroke and retinal degeneration, but the underlying therapeutic mechanisms are unknown. Because synaptic dysfunction, synapse loss, degeneration of neuronal processes, and neuronal death are hallmarks of neurological diseases and retinal degenerations, we tested whether hUTCs contribute to tissue repair and regeneration by stimulating synapse formation, neurite outgrowth, and neuronal survival. To do so, we used a purified rat retinal ganglion cell culture system and found that hUTCs secrete factors that strongly promote excitatory synaptic connectivity and enhance neuronal survival. Additionally, we demonstrated that hUTCs support neurite outgrowth under normal culture conditions and in the presence of the growth-inhibitory proteins chondroitin sulfate proteoglycan, myelin basic protein, or Nogo-A (reticulon 4). Furthermore, through biochemical fractionation and pharmacology, we identified the major hUTC-secreted synaptogenic factors as the thrombospondin family proteins (TSPs), TSP1, TSP2, and TSP4. Silencing TSP expression in hUTCs, using small RNA interference, eliminated both the synaptogenic function of these cells and their ability to promote neurite outgrowth. However, the majority of the prosurvival functions of hUTC-conditioned media was spared after TSP knockdown, indicating that hUTCs secrete additional neurotrophic factors. Together, our findings demonstrate that hUTCs affect multiple aspects of neuronal health and connectivity through secreted factors, and each of these paracrine effects may individually contribute to the therapeutic function of these cells.

Key words: cell therapy; regenerative medicine; retinal ganglion cells; synapse; thrombospondin; umbilical cord tissue-derived cells

Significance Statement

Human umbilical tissue-derived cells (hUTC) are currently under clinical investigation for the treatment of geographic atrophy secondary to age-related macular degeneration. These cells show great promise for the treatment of neurological disorders; however, the therapeutic effects of these cells on CNS neurons are not fully understood. Here we provide compelling evidence that hUTCs secrete multiple factors that work synergistically to enhance synapse formation and function, and support neuronal growth and survival. Moreover, we identified thrombospondins (TSPs) as the hUTC-secreted factors that mediate the synaptogenic and growth-promoting functions of these cells. Our findings highlight novel paracrine effects of hUTC on CNS neuron health and connectivity and begin to unravel potential therapeutic mechanisms by which these cells elicit their effects.

\section{Introduction}

Cell therapy is a promising strategy for the treatment of neurological disorders. Transplanted cells are thought to promote recovery and neuroprotection by replacing the damaged cells or by

Received April 9, 2015; revised Sept. 17, 2015; accepted 0ct. 15, 2015.

Author contributions: S.K. and C.E. designed research;S.K. and N.K. performed research;H.H.Y., I.R.H., N.S.D., and C.E. contributed unpublished reagents/analytic tools; S.K., N.K., H.H.Y., N.S.D., and C.E. analyzed data; S.K., N.S.D., and C.E. wrote the paper.

This work was supported by a contract with Janssen Research and Development. We thank Dr. II-hwan Kim and Dr. Scott Soderling (Department of Cell Biology, Duke University) for the generous gift of lentiviral packaging plasmids. providing trophic factors that enhance neural health and regeneration (Rao and Mattson, 2001; Lindvall and Kokaia, 2010; Popovich, 2012; Doeppner and Hermann, 2014; Atala, 2015). The umbilical cord is a commonly used cell source for therapeutic purposes due to ease of accessibility without ethical concerns. Several studies report that umbilical cord blood-derived cells can be potentially useful for the treatment of various types of neuro-

The work described was performed under a sponsored research agreement between Duke University and Janssen Research and Development. N.S.D. and I.R.H. are employees of Janssen Research and Development. The remaining authors declare no competing financial interests. 
degeneration (Lee et al., 2010, 2012; Park et al., 2012; Rowe et al., 2012; Achyut et al., 2014).

An alternative source of therapeutic cells is the umbilical tissue itself. Human umbilical tissue-derived cells (hUTCs) are isolated from whole cord tissue, devoid of blood, and are currently under clinical investigation for the treatment of geographic atrophy secondary to age-related macular degeneration (NCT01226628). These cells are karyotypically stable during in vitro culture (Lund et al., 2007), ensuring safety upon their transplantation. hUTCs are distinct from umbilical cord bloodderived cells as they do not express CD31 or CD45 (Lund et al., 2007), cell surface markers that are highly expressed on cord blood cells (Lund et al., 2007; Achyut et al., 2014).

The therapeutic potential of hUTC administration was demonstrated in various animal disease models (Lund et al., 2007; Zhang et al., 2011, 2012, 2013; Jiang et al., 2012; Moore et al., 2013). Delivery of hUTCs into animal models of stroke (Zhang et al., 2011, 2012, 2013; Jiang et al., 2012; Moore et al., 2013) and retinal degeneration (Lund et al., 2007) has shown that these cells enhance functional recovery and protect neurons from progressive degeneration. The lifespan of the transplanted cells varies with transplantation sites and methods, but the beneficial effects of the cells were measured 8-12 weeks after treatment (Lund et al., 2007; Jiang et al., 2012; Zhang et al., 2012, 2013).

Paracrine factors secreted by hUTCs, such as growth factors, cytokines, and chemokines, are thought to promote the therapeutic effects of these cells. Several hUTC-secreted growth factors with general neuroprotective effects have been identified, such as brainderived neurotrophic factor (BDNF) and interleukin-6 (Lund et al., 2007; Alder et al., 2012); however, the underlying therapeutic mechanisms of hUTCs are still unclear.

In this study, we investigated the direct effects of hUTCsecreted factors on CNS neurons. We postulated that hUTCs could enhance neuronal structure and function by promoting synaptic connectivity, supporting neuronal outgrowth, and sustaining neuronal survival. To examine this possibility, we used an in vitro purified primary neuronal culture system of rat retinal ganglion cells (RGCs) isolated from 7-day-old rat pups. This allowed us to dissect out the hUTC-neuron interactions that control different aspects of neuronal health. We found that hUTCs secrete factors that directly enhance neuronal survival, strongly trigger synapse formation, and promote neurite outgrowth.

Purified RGC cultures have been extensively used to determine the molecular mechanisms that promote neuronal survival and neurite outgrowth (Barres et al., 1988; Meyer-Franke et al., 1995; Goldberg and Barres, 2000). Moreover, this culture system was critical in elucidating that astrocytes secrete signals that control synapse formation between neurons (Pfrieger and Barres, 1997; Mauch et al., 2001; Ullian et al., 2001; Christopherson et al., 2005; Kucukdereli et al., 2011; Allen et al., 2012). Thrombospondin (TSP) family proteins TSP1 and TSP2 were identified as the necessary and sufficient astrocyte-secreted synaptogenic proteins that promote a strong increase in excitatory synapses made between RGCs (Christopherson et al., 2005) via their interactions with the neuronal receptor, calcium channel subunit $\alpha 2 \delta$-1 (Eroglu et al., 2009). Here we found that hUTCs secrete TSP family members TSP1, TSP2, and TSP4, which are essential for the ability of these cells to promote synapse formation and neurite outgrowth.

Correspondence should be addressed to Dr. Cagla Eroglu, Duke University, 307 Research Drive, Room 334, Nanaline Duke Building, Durham, NC 27710. E-mail: c.eroglu@cellbio.duke.edu.

DOI:10.1523/JNEUROSCI.1364-15.2015

Copyright $\odot 2015$ the authors $\quad 0270-6474 / 15 / 3515650-17 \$ 15.00 / 0$

\section{Materials and Methods}

Isolation and culture of primary rat RGCs and astrocytes. All experiments were conducted in accordance with the institutional animal care and use committee guidelines (Institutional Animal Care and Use Committee Protocols A-185-11-08 and A-173-14-07). RGCs were purified by sequential immunopanning from P7 (postnatal day 7) Sprague Dawley rat retinas (Charles River) of either sex as previously described (Winzeler and Wang, 2013). Briefly, retinas were dissected and dissociated with papain (6 U/ml, Worthington). Dissociated cells were panned first with Bandeiraea Simplicifolia Lectin I (Vector Laboratories)-coated Petri dishes to remove immune cells, cell debris, and fibroblasts. The unbound cells were transferred to a Petri dish coated with anti-Thyl (clone T11D7) antibody for specific isolation of RGCs. The purified RGCs were gently trypsinized and replated onto poly-D-lysine and laminin-coated glass coverslips in 24-well plates (35,000 cells/coverslip). RGCs were cultured in a serum-free growth medium containing B27 (Invitrogen), BDNF, ciliary neurotrophic factor (CNTF), insulin, and forskolin (for full recipe of the media, see Winzeler and Wang, 2013).

Cortical astrocytes were isolated from P1 Sprague Dawley rat pups of either sex using standard methods as described previously (McCarthy and de Vellis, 1980). For astrocyte coculture, transwell inserts (BD Biosciences) were prepared by seeding 125,000 cortical astrocytes per insert in astrocyte growth media (described by McCarthy and de Vellis, 1980). The next day, astrocyte growth media were replaced with RGC growth media, and the transwell inserts were transferred into the 24-well plate containing the 4 DIV RGCs on coverslips.

hUTC preparation. Human umbilical cords were obtained with donor consent following live births. Tissues were minced and enzymatically digested. After almost complete digestion with DMEM-low glucose $(\mathrm{Lg})$ (SAFC Biosciences) containing a mixture of $0.5 \mathrm{U} / \mathrm{ml}$ collagenase (Serva Electrophoresis), $5 \mathrm{U} / \mathrm{ml}$ neutral protease (Serva Electrophoresis), and 2 $\mathrm{U} / \mathrm{ml}$ hyaluronidase (Cumulase; Origio), the cell suspension was filtered through a $70 \mu \mathrm{m}$ filter, and the supernatant was centrifuged at $250 \times \mathrm{g}$. Isolated cells were washed in DMEM-Lg several times and plated at a density of 5000 cells $/ \mathrm{cm}^{2}$ in DMEM-Lg containing 15\% (v/v) FBS (SAFC Biosciences) $\left(5 \%\right.$ carbon dioxide, $\left.37^{\circ} \mathrm{C}\right)$. When cells reached $\sim 70 \%$ confluence $(\sim 3-4 \mathrm{~d})$, they were passaged using TrypLE (Invitrogen). Cells were expanded several times and banked. Cryopreserved hUTCs (16-20 population doublings) were used for the present study.

Normal human dermal fibroblast (NHDF) preparation. NHDFs, Passage 1 (adult skin) were obtained from Lonza. Cells were expanded and cryopreserved at Passage 4, according to the manufacture's protocol.

Coculture experiments. For coculture experiments, 25,000 hUTCs were seeded into transwell inserts in hUTC growth media a day before the coculture with RGCs. This seeding density was optimal for hUTCs because higher seeding densities led to overconfluence. On the day of coculture, the hUTC growth media were replaced with RGC growth media, and transwell inserts were transferred into the 24-well plates with 4 DIV RGCs that are grown on glass coverslips.

NHDFs were cultured in fibroblast basal medium (Lonza) using manufacturer's recommendations. For coculture with RGCs, 150,000 NHDFs were seeded into transwell inserts in fibroblast basal media day before the coculture with RGCs. The next day, fibroblast basal media were replaced with RGC growth media, and the transwell inserts were transferred into the 24 -well plate containing the 4 DIV RGCs on coverslips.

Preparation of conditioned media. Pure astrocyte cultures or hUTCs were grown in $10 \mathrm{~cm}$ tissue culture dishes (Corning) in their own growth media until they were $70 \%$ confluent. Cells were then washed twice with warm DPBS (Invitrogen), and $10 \mathrm{ml}$ of conditioning media, which is composed of Neurobasal (Invitrogen) supplemented with L-glutamine ( $2 \mathrm{~mm}$, Invitrogen), sodium pyruvate (1 mM, Invitrogen), penicillin (100 $\mathrm{U} / \mathrm{ml})$, and streptomycin $(100 \mu \mathrm{g} / \mathrm{ml}$, Invitrogen), was added to each dish. Media were conditioned by cells for $5 \mathrm{~d}$. Cell-free conditioned media were collected and concentrated 10 times using $5 \mathrm{kDa}$ molecular weight cutoff Vivaspin 20 centrifugal concentrators (Sartorius). The protein concentration of each conditioned medium was measured by the 
A

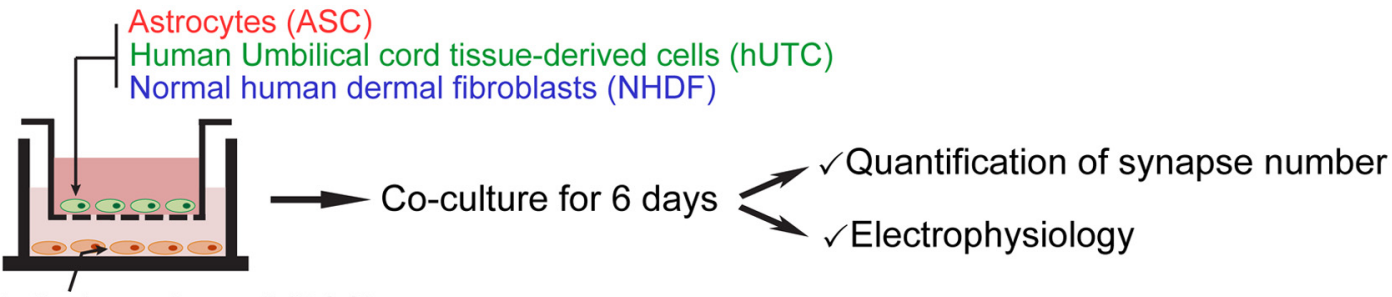

Retinal ganglion cell (RGC) neurons

B
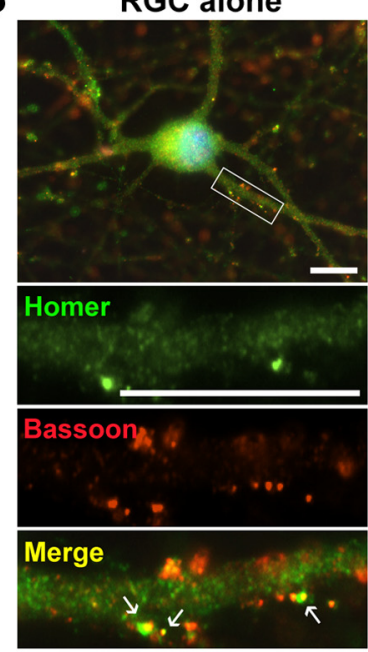

C
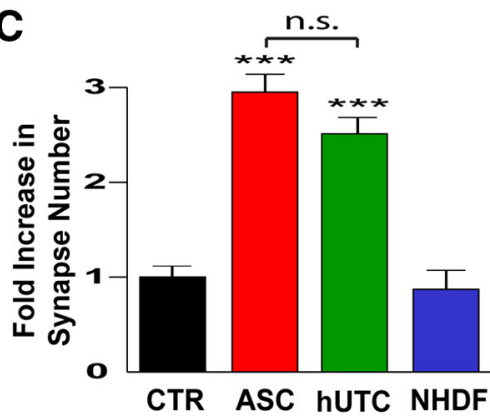

ASC

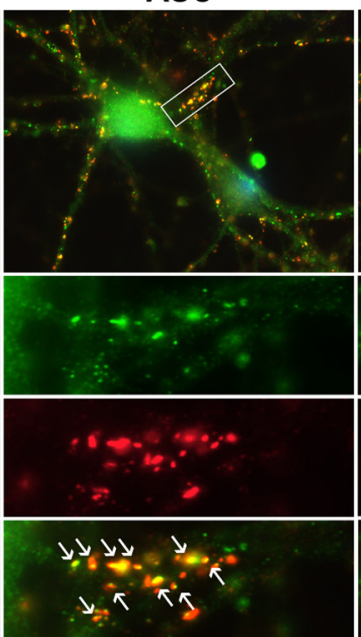

hUTC

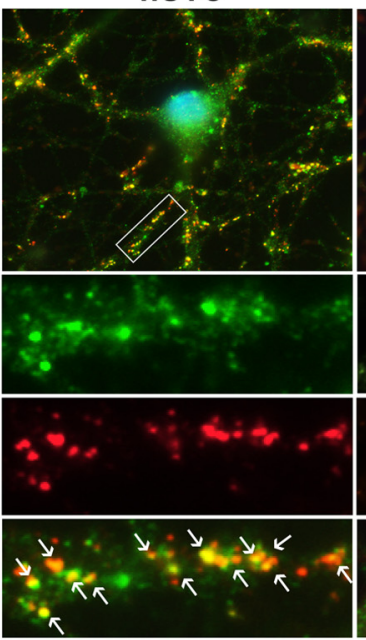

NHDF

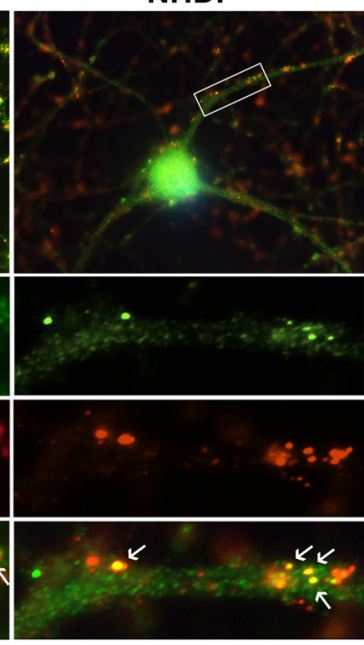

D

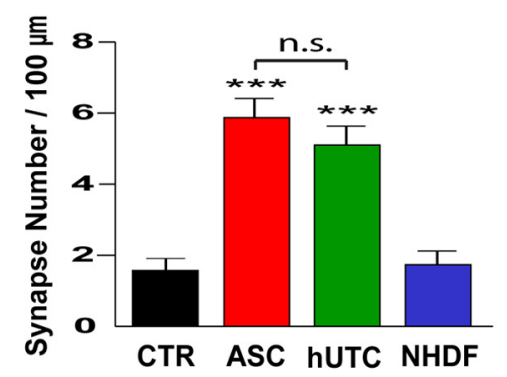

Figure 1. hUTCs induce synapse formation between cultured RGCS. $\boldsymbol{A}$, Schematic representation of the experimental design. Purified RGCs are either cultured alone or cocultured with hUTCS, NHDF, or rat ASCs in transwell inserts for $6 \mathrm{~d}$. The number and function of synapses are determined by immunocytochemistry- and electrophysiology-based assays, respectively. $\boldsymbol{B}$, Representative images of RGCs stained with antibodies specific for presynaptic (Bassoon, red) and postsynaptic (Homer, green) proteins. Bottom, Inlets (white boxes) are shown in higher magnification. White arrows indicate the colocalized synaptic puncta (merge, yellow). Scale bar, $20 \mu \mathrm{m}$. C, Quantification of fold increase in the number of colocalized synaptic puncta ( $n=59-161$ cells/condition). D, Quantification of fold increase in synaptic density (number of synapses per unit dendritic length, $n=30$ cells/condition) reveals that hUTCs, like ASCs, induce excitatory synapse formation between cultured RGCS. Fold increase is calculated by normalizing the number of synapses per cell with the number of synapses per cell in RGCs alone (CTR) condition. ${ }^{* * *} p<0.0001$. n.S., Not significant.

Bradford assay (Thermo Scientific) following the manufacturer's recommendations. Aliquots of astrocyte-conditioned media (ACM) and hUTC-conditioned media (UCM) in low protein-binding tubes (Eppendorf) were rapidly frozen in liquid nitrogen and stored at $-80^{\circ} \mathrm{C}$ until use. To fractionate UCM with different molecular weight cutoffs 30 and $100 \mathrm{kDa}$, Vivaspin 20 centrifugal concentrators were used. To collect 5-100 kDa UCM fractions, flow-through of $100 \mathrm{kDa}$ Vivaspin 20 was concentrated with $5 \mathrm{kDa}$ Vivaspin 20 concentrators. For treatments, frozen aliquots were allowed to slowly melt on ice, and conditioned media were added into ice-cold RGC growth media (synapse and outgrowth assays) or minimal media (survival assays) at the desired concentrations.

Quantification of synapse number by immunocytochemistry (synapse assay). To test the effects of hUTC coculture or UCM on synaptogenesis, 35,000 RGCs were cultured alone on glass coverslips for 4 DIV and transwell inserts or conditioned media were added on 4 DIV. To block TSPinduced synapse formation, $32 \mu \mathrm{M}$ gabapentin (GBP) was added together with the conditioned media as described previously (Eroglu et al., 2009). The cocultured cells received fresh growth media on 7 DIV. When conditioned media were used, growth media supplemented with condi- tioned media were provided at 7 DIV. On 10 DIV, RGCs were fixed with $4 \%$ PFA (w/v) and stained for presynaptic and postsynaptic markers bassoon (mouse anti-bassoon, 1:1000, RRID: AB_2038857, Enzo) and homer-1 (rabbit anti-homer, 1:500, RRID: AB_1966438, Synaptic Systems). Alexa-conjugated secondary antibodies (Invitrogen, goat anti rabbit AlexaFluor-488, 1:1000; RRID: AB_10563748 and goat anti mouse AlexaFluor-594, 1:500; RRID: AB_10561507) were used for detection. Coverslips were mounted in Vectashield mounting medium with DAPI (Vector Laboratories) on glass slides (VWR Scientific). RGCs were imaged on a Zeiss Axioimager M1 Epifluorescence Microscope (Carl Zeiss) using a $63 \times$ objective. Morphologically healthy single cells that were at least two cell diameters from their nearest neighbor were identified randomly by DAPI fluorescence. At least $15-20$ cells per condition were imaged and analyzed per experiment, and the results presented are the average of two or three independent experiments. Captured images were analyzed for colocalized synaptic puncta with a custom plug-in (written by Barry Wark, available upon request from C.E.) for the National Institutes of Health image-processing package ImageJ. The details of the staining protocol and the quantification method are described previously 
A
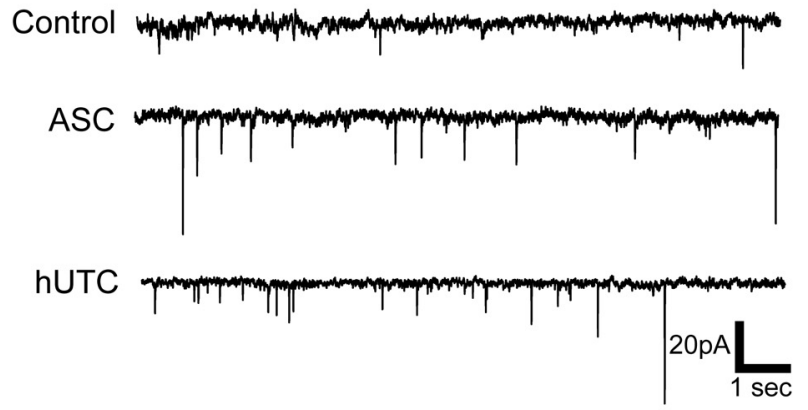

B

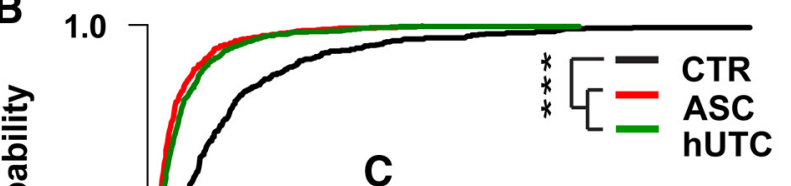

C

0.5

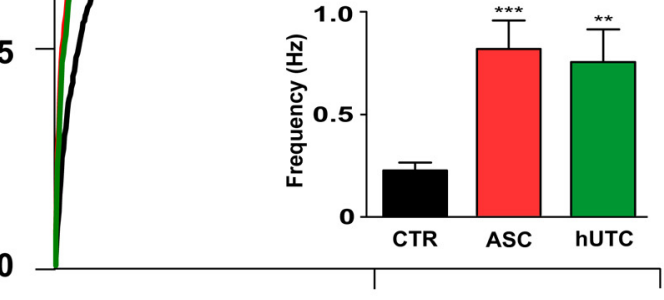

30

60

Inter-event interval (sec)

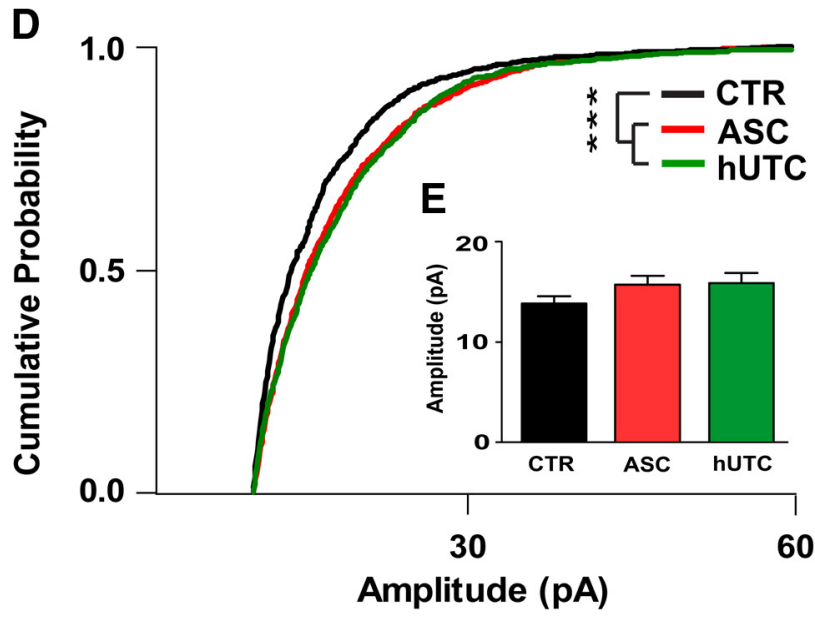

Figure 2. Coculture-induced synapses are electrophysiologically functional. $\boldsymbol{A}$, Example traces from whole-cell patch-clamp recordings showing $\mathrm{mEPSC}$. Cumulative probability plots of $(\boldsymbol{B})$ interevent interval and $(\boldsymbol{C})$ quantification of mean frequency of mEPSCs reveal that $\mathrm{CO}^{-}$ culture with hUTCs or ASCs induces significant increases in the number of synaptic events. $\boldsymbol{D}$, Cumulative probability plot of $\mathrm{mEPSC}$ amplitudes demonstrates a significant increase in largeamplitude events in RGCs that were cocultured with hUTCs or ASCs compared with RGCs cultured alone. $\boldsymbol{E}$, However, the mean values of mEPSC amplitudes were not significantly different between conditions. For electrophysiology experiments, $n=15$ cells/condition. Data are mean \pm SEM. ${ }^{* * *} p<0.0001 .{ }^{* *} p<0.001$.

(Ippolito and Eroglu, 2010). Synaptic densities (number of synapses per neurite length) were determined by counting the number of colocalized synaptic puncta per $100 \mu \mathrm{m}$ dendrite. For this analysis, one proximal dendrite/cell was randomly chosen per image. The synaptic density results presented are from one experiment with 30 cells/condition.

Electrophysiological recordings from RGCs. Miniature EPSCs (mEPSCs) were recorded by whole-cell patch clamp at a holding potential of -70 $\mathrm{mV}$. The cells were maintained under continuous perfusion of the extracellular solution at $23^{\circ} \mathrm{C}-24^{\circ} \mathrm{C}$ with $0.2 \mathrm{ml} / \mathrm{min}$ flow rate. The extra- cellular solution contained the following: $124 \mathrm{~mm} \mathrm{NaCl}, 2.5 \mathrm{~mm} \mathrm{KCl}, 2$ mм CaCl$, 1 \mathrm{~mm} \mathrm{MgCl}_{2}, 26 \mathrm{~mm} \mathrm{NaHCO}_{3}, 1.2 \mathrm{~mm} \mathrm{NaH}_{2} \mathrm{PO}_{4}, 10 \mathrm{~mm}$ D-glucose, pH 7.4. TTX (1 $\mu \mathrm{M}, \mathrm{Abcam})$ was added in the extracellular solution during recording. The internal solution in patch pipettes $(2.5-5$ $\mathrm{M} \Omega$ ) contained the following: $120 \mathrm{~mm}$ cesium methane sulfonate, $5 \mathrm{~mm}$ $\mathrm{NaCl}, 10 \mathrm{~mm}$ tetraethylammonium chloride, $10 \mathrm{~mm}$ HEPES, 4 mm lidocaine $\mathrm{N}$-ethyl bromide, $1.1 \mathrm{~mm}$ EGTA, 4 mm magnesium ATP, and 0.3 mm sodium GTP, $\mathrm{pH}$ adjusted to 7.2 with $\mathrm{CsOH}$ and osmolality set to $300 \mathrm{mOsm}$ with sucrose. Signals were recorded by MultiClamp 700B amplifier (Molecular Devices) and filtered at $10 \mathrm{kHz}$ and digitized at 20 $\mathrm{kHz}$ with a Digidata 1440A digitizer (Molecular Devices). In the wholecell configuration, recordings were only accepted when the series resistance is $\angle 20 \mathrm{M} \Omega$. All data were analyzed using peak detection software in pCLAMP10 (Molecular Devices). Data presented are acquired from 15 cells/condition that were recorded $>3$ independent experiments.

Neurite outgrowth assay. The RGCs were plated onto poly-D-lysine and mouse laminin $(20 \mathrm{ng} / \mathrm{ml})$-coated glass coverslips at low density (1500 cells/coverslip) for $24 \mathrm{~h}$ and then were fixed with $4 \%$ PFA (w/v) and immunostained with rabbit anti- $\beta$ tubulin antibody (LI-COR, RRID: AB_1850029), followed with goat anti-rabbit AlexaFluor-488 to visualize the neurites. To test neurite outgrowth under pathological (i.e., growthinhibiting) culture conditions, the RGCs (1500 cells/coverslip) were plated onto coverslips that were coated with various concentrations of chondroitin sulfate proteoglycan (CSPG, EMD Millipore), Nogo-A (R\&D Systems), or in the presence of soluble myelin basic protein (MBP, $10 \mu \mathrm{g} / \mathrm{ml}$, Sigma-Aldrich). After $24 \mathrm{~h}$, neurites were visualized by incubating with CellTracker Red CMPTX dye (Invitrogen) for $15 \mathrm{~min}$ followed by fixation with $4 \%$ PFA (w/v). Images of single RGCs with their neurites were captured using a $20 \times$ objective on a Zeiss Axioimager M1 Epifluorescence Microscope (Carl Zeiss). At least 30 cells per condition were imaged and analyzed per experiment, and the results presented are the average of two or three independent experiments. Neuronal morphology was analyzed using neurite outgrowth application module in MetaMorph software (Molecular Devices). Sholl analysis was performed using a plug-in for Fiji as described previously (Ferreira et al., 2014).

Survival assay. For survival assays, RGCs were plated directly onto 24 -well tissue culture plates (7500 cells/well). Wells were coated with poly-D-lysine and laminin. Cells were cultured in a minimal media containing Neurobasal (Invitrogen), SATO supplement $(100 \mu \mathrm{g} / \mathrm{ml}$ transferrin, $100 \mu \mathrm{g} / \mathrm{ml} \mathrm{BSA,} 60 \mathrm{ng} / \mathrm{ml}$ progesterone, $16 \mu \mathrm{g} / \mathrm{ml}$ putrescine, 40 $\mathrm{ng} / \mathrm{ml}$ sodium selenite), $N$-acetylcysteine $(5 \mu \mathrm{g} / \mathrm{ml})$, triiodothyronine (4 $\mu \mathrm{g} / \mathrm{ml})$, L-glutamine $(2 \mathrm{~mm})$, penicillin $(100 \mathrm{U} / \mathrm{ml})$, streptomycin $(100$ $\mu \mathrm{g} / \mathrm{ml})$, sodium pyruvate $(1 \mathrm{mM})$, and forskolin $(5 \mu \mathrm{M})$. To test the effects of UCM and ACM on survival, the minimal media were supplemented with various concentrations of conditioned media in the absence/presence of forskolin, BDNF $(200 \mathrm{ng} / \mathrm{ml})$, or CNTF $(40 \mathrm{ng} / \mathrm{ml})$ The cell viability was assessed at 3 DIV by using the LIVE/DEAD Viability Kit for mammalian cells (Invitrogen) following the manufacturer's instructions. The viability counts were performed $15 \mathrm{~min}$ after the application of the kit agents, and representative images were captured with Zeiss Axio Observer A1 Epifluorescence Microscope (Carl Zeiss) using a 20× objective. At least 10 fields per treatment were counted in each experiment, and the results presented are an average of two or three experiments. Percentage survival was calculated as the number of live cells divided by the total of number of dead and live cells $\times 100$.

Production of lentivirus for TSP knockdown. shRNA construct pools cloned into pLKO.1-puro vectors that target human THBS1, THBS2, or THBS4 mRNA (translated to TSP1, TSP2, and TSP4, respectively) were purchased from Thermo Scientific. The empty pLKO.1 puro vector was purchased from Addgene (plasmid 8453) and used as knockdown control. Knockdown efficiency of individual constructs was determined by transfection into hUTCs. An shRNA construct for each TSP that demonstrated the most effective knockdown was chosen for subsequent lentivirus production.

To make the lentivirus, 293T lentiviral-packaging cells were seeded at $8 \times 10^{6}$ cells per T75 flask a day before transfection. The next day, pLKO.1-puro lentiviral plasmid-containing shRNA for THBS1 (clone TRCN00224), THBS2 (clone TRCN53972), THBS4 (clone TRCN54048), or knockdown control (Addgene plasmid 8453) was 


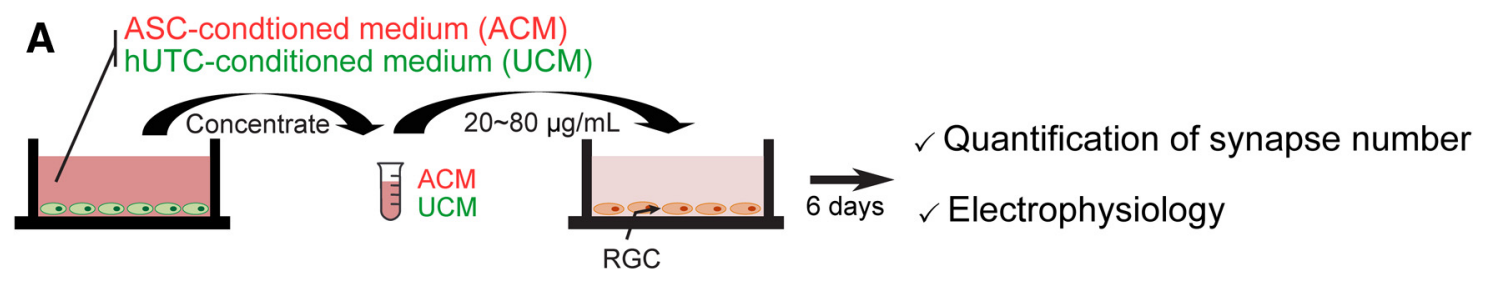

B RGC alone

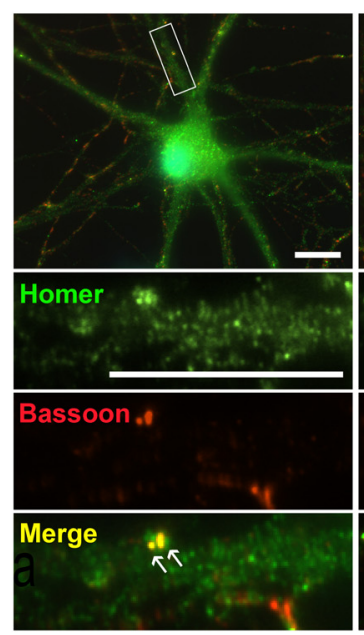

C

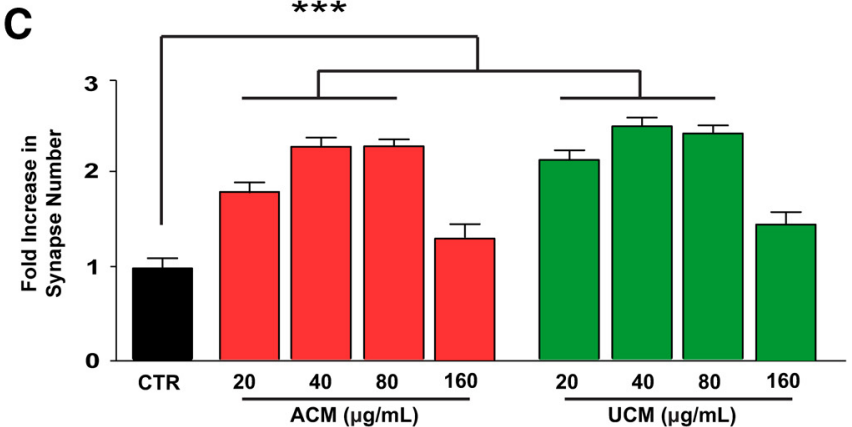

ACM $(80 \mu \mathrm{g} / \mathrm{mL})$
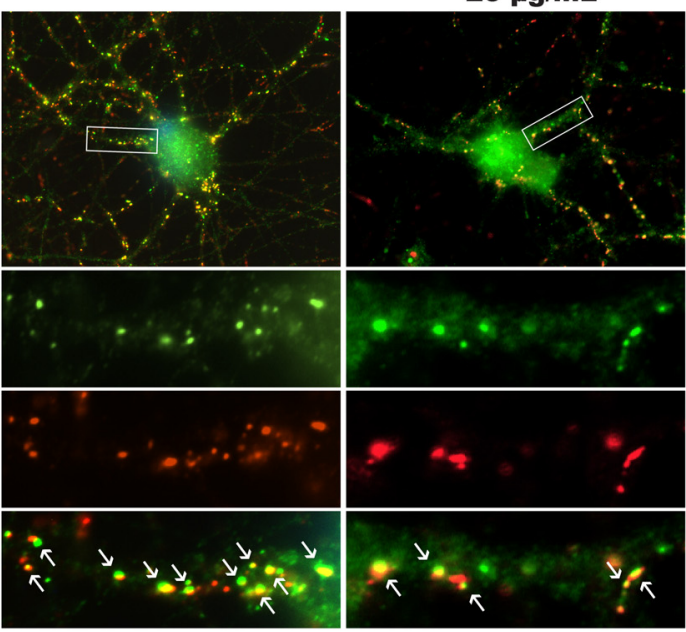

UCM

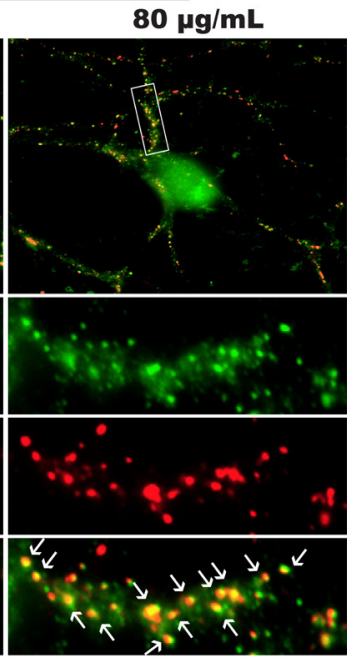

D

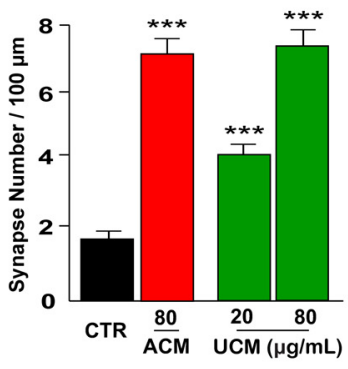

Figure 3. UCM induce synapse formation between cultured RGCS. A, Schematic representation of the experimental design. Purified RGCs are treated with UCM (at various concentrations) or ACM for $6 \mathrm{~d}$. The number and function of synapses are determined by immunocytochemistry- and electrophysiology-based assays, respectively. $\boldsymbol{B}$, Representative images of RGCs stained with antibodies specific to presynaptic (Bassoon, red) and postsynaptic (Homer, green) proteins. Bottom, Inlets (white boxes) are shown in higher magnification. White arrows indicate the colocalized synaptic puncta (merge, yellow). Scale bars, $20 \mu \mathrm{m}$. Quantification of ( $\boldsymbol{C}$ ) fold increase in synapse numbers $(n=65-157$ cells/condition) and $(\boldsymbol{D})$ synaptic density (number of synapses per unit dendritic length, $n=30$ cells/condition) reveal that UCM, like ACM, induce excitatory synapse formation between cultured RGCs. Fold increase in synapse numbers is calculated by normalizing the number of colocalized synaptic puncta per cell with the number of synapses in the RGC alone condition. Data are mean \pm SEM. ${ }^{* *} p<0.0001$.

transfected into $293 \mathrm{~T}$ cells. For scrambled shRNA controls, oligos containing sense and antisense scrambled sequences of THBS1 (5'-ATAACTC CGATCGTTCAATAT-3'), THBS2 (5'-GTTACATCTCGATACGATACA$3^{\prime}$ ), and THBS4 (5'-ATATAAGACGCTAGATCCACA-3') shRNAs were used. The scrambled oligos were annealed and cloned into pLKO.1-puro for production of lentivirus. Packaging plasmids, $\delta$ R8.2, and VSV-G were cotransfected using X-tremeGENE transfection reagent (Roche) following the manufacturer's recommendation. Lentiviral supernatants were collected twice at 48 and $72 \mathrm{~h}$ after transfection and filtered through a $0.45 \mu \mathrm{m}$ filter (Millipore). The viral particles were detected using Lenti-X GoStix (Clontech). The filtered supernatants were used to infect hUTCs after supplementation with polybrene $(2 \mu \mathrm{g} / \mathrm{ml}$, Sigma). The transduced hUTCs were further selected by adding puromycin $(900 \mathrm{ng} / \mathrm{ml})$ to the hUTC media for $5 \mathrm{~d}$ before conditioning media for the RGC experiments. Conditioned media were prepared as described above.

Western blot analysis of conditioned media. A total of 10-20 $\mu \mathrm{g}$ of conditioned media was prepared for PAGE in $5 \times$ Laemmli loading buffer (Thermo Scientific) containing 5\% $\beta$-mercaptoethanol (v/v). The proteins were denatured at $95^{\circ} \mathrm{C}$ for $15 \mathrm{~min}$. Proteins were sepa- rated in 10\% SDS-PAGE gels (Bio-Rad) and were then transferred onto PVDF membranes (Millipore). To detect TSPs, goat anti-human TSP1 (1:250, RRID: AB_2201958), TSP2 (1:250, RRID: AB_2202068), and TSP4 (1:200, RRID: AB_2202087) (R\&D Systems) were used. For loading control, another hUTC-secreted protein, called Hevin/ SPARCL1, was detected using a goat anti-Hevin antibody $(1: 250$, RRID: AB_2195103, R\&D Systems). HRP-conjugated anti-goat antibody (R\&D Systems, 1:5000) was used as secondary antibody. The detection was performed with a GE Healthcare ECL Western Blotting Analysis System kit (GE Healthcare) or SuperSignal West Femto Maximum Sensitivity Substrate (Thermo Scientific) following the manufacturer's recommendation.

Production and purification of recombinant TSPs. Purified recombinant human TSP1 was purchased from R\&D Systems. For TSP2 purification, a CHO cell line-expressing mouse TSP2 was used to produce conditioned media. The secreted recombinant TSP2 was purified from the culture media as previously described (Oganesian et al., 2008) using affinity chromatography procedures with HiTRAP heparin HP (GE Healthcare). For TSP4, a 6-histidine tagged rat TSP4 construct (pcDNA3-TSP4, as 
A

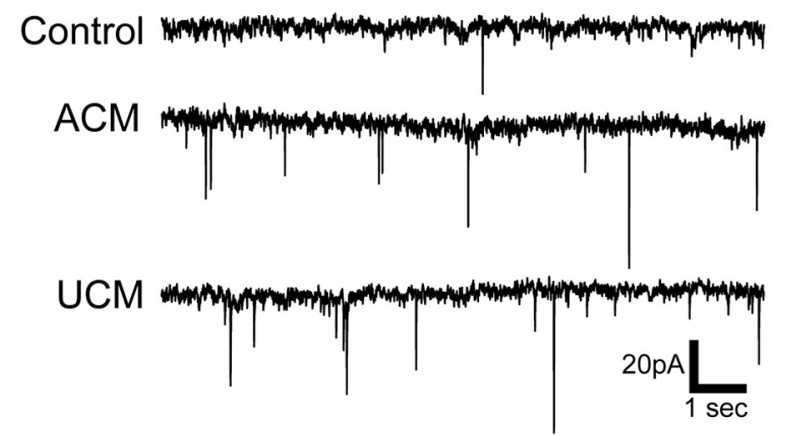

B

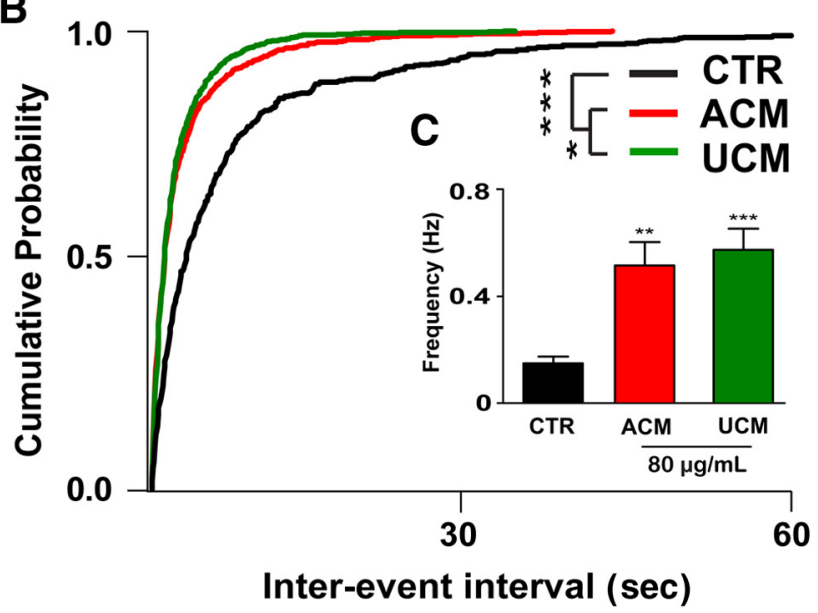

D

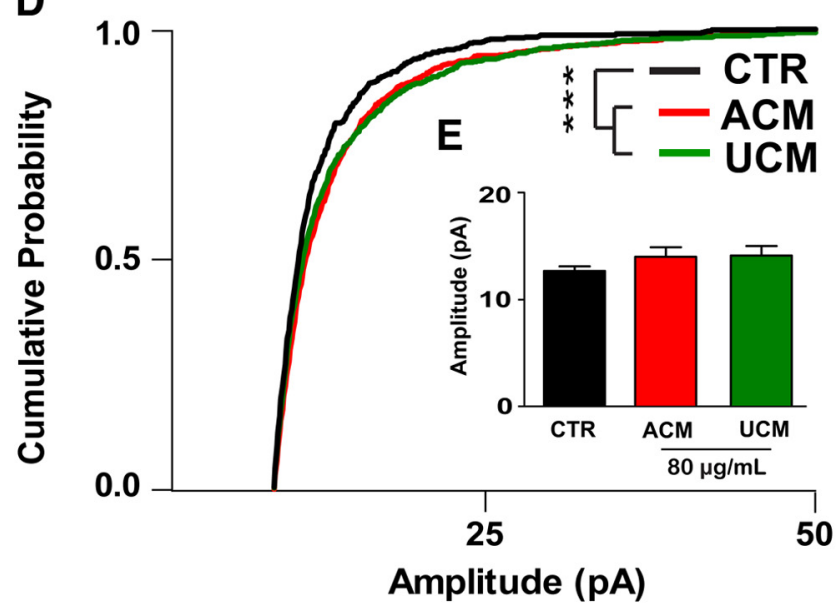

Figure 4. hUTC-secreted factors induce functional synapse formation between cultured $\mathrm{RGCS}$. A, Example traces from whole-cell patch-clamp recordings showing mEPSCs from RGCs cultured alone or treated with ACM $(80 \mu \mathrm{g} / \mathrm{ml})$ or UCM $(80 \mu \mathrm{g} / \mathrm{ml})$. Cumulative probability plots of $(\boldsymbol{B})$ interevent interval and $(\boldsymbol{C})$ quantification of mean frequency of $\mathrm{mEPSC}$ s reveal that treatment with UCM or ACM induces a significant increase in the number of synaptic events. $\boldsymbol{D}$, Cumulative probability plot of $\mathrm{mEPSC}$ amplitudes demonstrates a significant increase in largeamplitude events when RGCs were treated with UCM or ACM compared with RGCs cultured alone. $\boldsymbol{E}$, However, the mean values of $\mathrm{mEPSC}$ amplitudes were not significantly different between conditions. For electrophysiology experiments, $n=15$ cells/condition. Data are mean \pm SEM. ${ }^{* * *} p<0.0001 .{ }^{* *} p<0.001 .{ }^{*} p<0.05$.

described by Kim et al., 2012) was transfected into HEK293 cells using Lipofectamine 2000 (Invitrogen) following the manufacturer's instructions. The secreted recombinant TSP4 was purified from the culture media by Ni-chelating chromatography using Ni-NTA resin (QIAGEN) following the manufacturer's instructions. Purified recombinant TSPs were concentrated up to $1 \mathrm{mg} / \mathrm{ml}$ with $30 \mathrm{kDa}$ cutoff Vivaspin 20 (Sartorius), and aliquots were rapidly frozen in liquid nitrogen and were stored at $-80^{\circ} \mathrm{C}$ until use.

Statistical analysis. Statistical analyses of the quantified data were done using one-way ANOVA followed by each pair, Student's $t$ (Fisher's LSD) post test. For Sholl analyses of neurite outgrowth assays, ANCOVA was performed. For analyses of cumulative probabilities of mEPSCs, Kruskal-Wallis test followed by Dunn's multiple-comparison post hoc test was used. JMP Genomics 5 embedded with SAS 9.2 software (SAS) was used for all statistical analyses of the data. All data were expressed as mean \pm SEM.

\section{Results}

hUTC-secreted factors induce functional synapse formation To determine whether the hUTCs secrete synaptogenic factors, we investigated the changes in the number and function of synapses made between purified RGCs when they were cocultured with hUTCs in transwell inserts. RGCs cocultured with primary rat astroglial cultures (ASCs) provided a positive control in this assay because astrocytes are known to strongly increase synapse numbers and enhance synaptic activity (Pfrieger and Barres, 1997; Ullian et al., 2001). On the other hand, RGCs treated with NHDF provided a negative control because they did not induce significant functional or structural recovery in a model of retinal degeneration (Lund et al., 2007). After 4 DIV, RGCs were cocultured with hUTCs, ASCs, or NHDF for an additional $6 \mathrm{~d}$, and the number of synapses was assessed by immunostaining with a pair of presynaptic and postsynaptic proteins: bassoon and homer, respectively (Fig. 1A). Synapses were determined as the colocalization of presynaptic and postsynaptic markers using methods described previously (Ippolito and Eroglu, 2010) (Fig. 1B, arrows). We found that, similar to ASCs, hUTCs strongly induce the formation of excitatory synapses between RGCs compared with RGCs cultured alone (Fig. 1B,C, one-way ANOVA, $p<0.0001$ ). Coculture with NHDF did not induce a significant increase in synapse number (Fig. $1 B, C$, one-way ANOVA, $p<0.0001$ ). Quantification of the number of synapses per unit neurite length revealed that hUTCs enhance synapse numbers primarily by increasing the synapse density (Fig. $1 D$, one-way ANOVA, $p<0.0001$ ).

To determine how hUTCs affect synaptic function, we performed whole-cell patch-clamp recordings to measure the mEPSCs. RGCs were either cultured alone or in the presence of hUTCs or ASCs (Fig. 1A). Similar to astrocytes, coculture of RGCs with hUTCs led to a significant increase in the frequency of the synaptic events (Fig. $2 A-C$, Kruskal-Wallis test, $p<$ 0.0001; Fig. $2 C$, one-way ANOVA, $p<0.0001$ ), which is in line with the robust increase we observed in the number of synapses (Fig. 1B-D). hUTCs also significantly increased the amplitude of potsynaptic currents demonstrating that, like astrocytes, hUTCs strengthen synaptic activity (Fig. 2D, Kruskal-Wallis test, $p<$ 0.0001). Together, these results show that hUTCs can induce excitatory synapse formation and enhance synaptic function in cultured RGCs, similar to ASCs.

To confirm that the synaptogenic effect of hUTCs is mediated via secreted factors and to determine whether secretion of these synaptogenic signals requires any feedback from neurons, we cultured hUTCs alone and collected UCM (Fig. 3A). We then treated RGCs with UCM and assessed the effect of conditioned media on synapse number and function using the same assays as in Figure 1 (Fig. 3A). We found that addition of UCM is sufficient to induce synapse formation similar to the hUTCs in transwell inserts (Fig. 3B-D, one-way ANOVA, $p<0.0001$ ). UCM's effect 
A
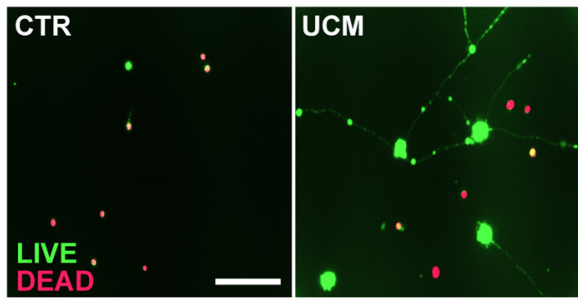

C

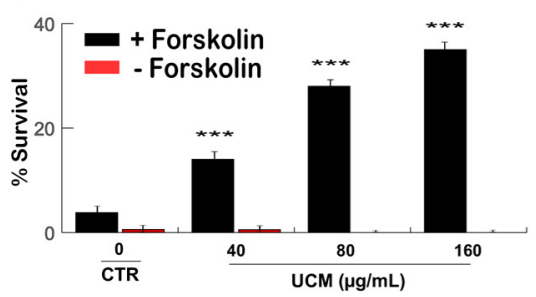

D

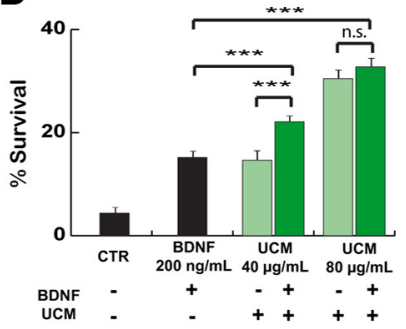

B

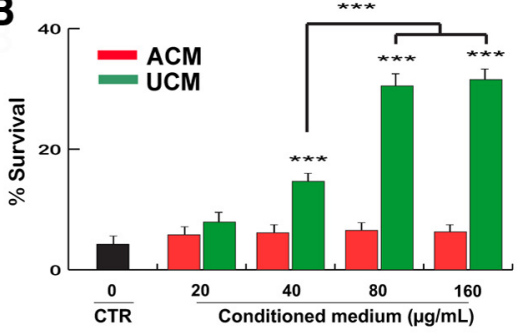

Figure 5. hUTC-secreted factors promote RGC survival. A, Representative images of RGCS treated with survival assay reagents: Calcein-AM for live cells (green) and ethidium homodimer-1 for dead cells (red). Scale bar, $100 \mu \mathrm{m}$. B, Quantification of RGC survival in the presence of various concentrations of ACM and UCM compared with RGCs cultured in minimal media (CTR). $n=9$ or 10 microscopic fields/condition. C, The UCM-mediated survival effects are forskolin-dependent at all concentrations of UCM tested ( $n=9-18$ microscopic fields/condition). The survival effect of UCM $(40 \mu \mathrm{g} / \mathrm{ml})$ is additive to that of (D) BDNF and (E) CNTF. $n=18-20$ microscopic field/condition. Data are mean \pm SEM. ${ }^{* * *} p<0.0001$. n.s., Not significant.
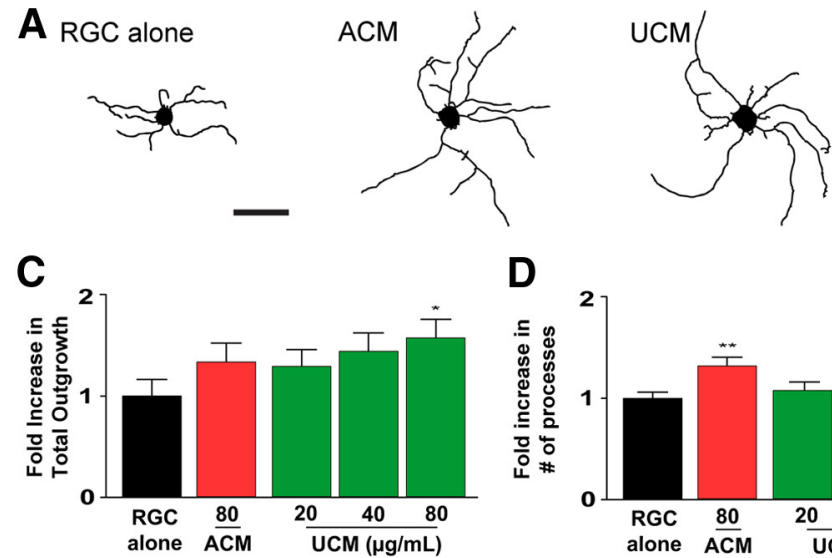

D

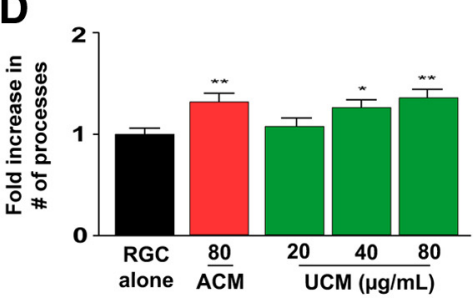

E

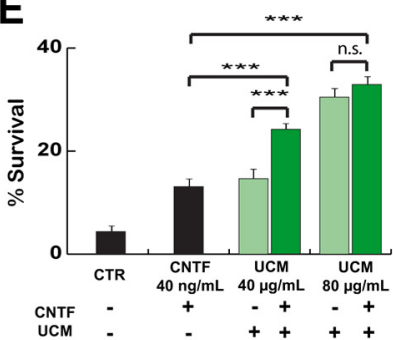

B

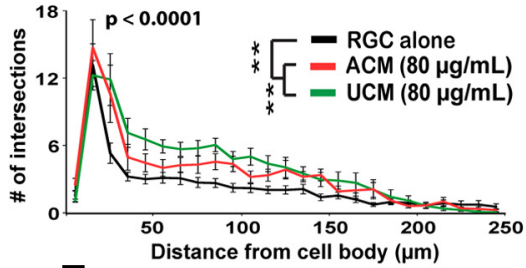

E

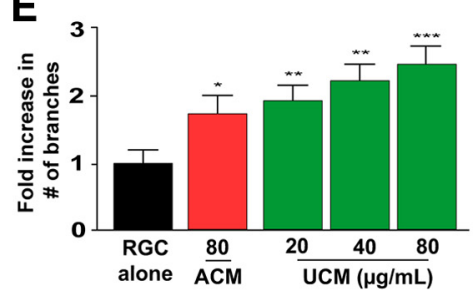

Figure 6. hUTC-secreted factors promote neurite outgrowth. $\boldsymbol{A}$, Representative skeletonized traces of RGCs either cultured alone or treated with ACM or UCM. Scale bar, $100 \mu \mathrm{m}$. $\boldsymbol{B}$, Sholl analysis of neurite complexity demonstrates that RGCS treated with conditioned media have increased elaboration compared with RGCs cultured alone ( $n=20-24$ cells/condition). Quantification of (C) total neurite outgrowth, $(\boldsymbol{D})$ number of processes, and $(\boldsymbol{E})$ number of branches demonstrate significant increases when RGCs were treated with UCM or ACM compared with RGCs cultured alone $(n=$ $25-36$ cells/condition). Graphs are presented as the fold increase normalized to the value of the RGC alone condition. Data are mean \pm SEM. ${ }^{* * *} p<0.0001 .{ }^{* *} p<0.001 .{ }^{*} p<0.05$.

on synaptogenesis was concentration-dependent (Fig. $3 B, C$, each pair Student's $t$ test, $p<0.0001)$. UCM exerted its full synaptogenic activity at concentrations between 20 and $80 \mu \mathrm{g}$ total protein/ml culture media. In addition, mEPSCs recording of RGCs treated with UCM demonstrated significant increase in the frequency of the synaptic events (Fig. $4 A-C$, Kruskal-Wallis test, $p<0.0001$; Fig. $4 C$, one-way ANOVA, $p<0.0001$ ) and the amplitude of postsynaptic currents (Fig. 4D,E, Kruskal-Wallis test, $p<$ 0.0001) comparable with ACM (positive control). These results show that hUTCs induce synapse formation through soluble secreted factors. Because UCM can work as efficiently as hUTC coculture, feedback from neurons, which can only be provided during coculture, is not necessary for this function of hUTCs.

Together, our results demonstrate that hUTCs strongly induce synapse formation and enhance synaptic function via secreted factors. These results suggest that the powerful synaptogenic effect of hUTCs may contribute to the functional recovery that is induced by the delivery of these cells to animal disease models.

\section{UCM contain factors that promote RGC survival and neurite outgrowth}

In addition to the functional recovery that was observed after hUTC transplantations, previous studies in animal disease models revealed a strong effect of these cells on the preservation of the neural structures (Lund et al., 2007; Zhang et al., 2011, 2012; Jiang et al., 2012; Moore et al., 2013). Therefore, using the RGC culture system, we next examined the effects of UCM on neuronal survival and neurite outgrowth. To assay for the survivalpromoting activity of the UCM, RGCs were cultured for 3 DIV in a minimal media, which lacked the media supplement B27 and growth factors BDNF, CNTF, and insulin, but contained forskolin (referred as CTR for minimal media control condition). Under these minimal media conditions, $<5 \%$ of the RGCs survive at the end of 3 


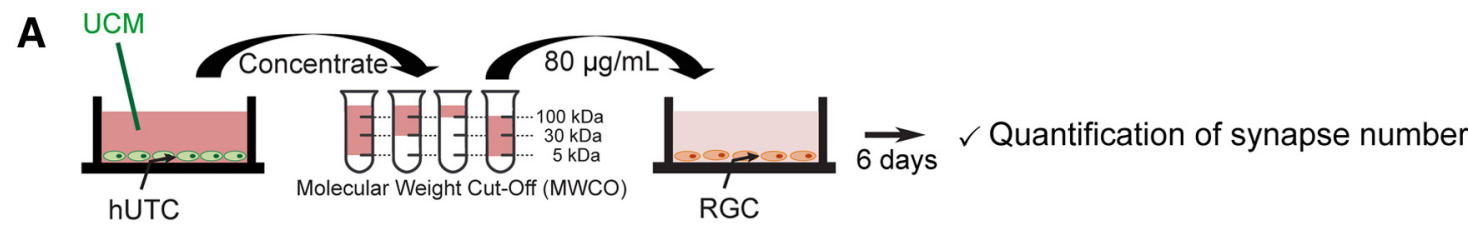

B
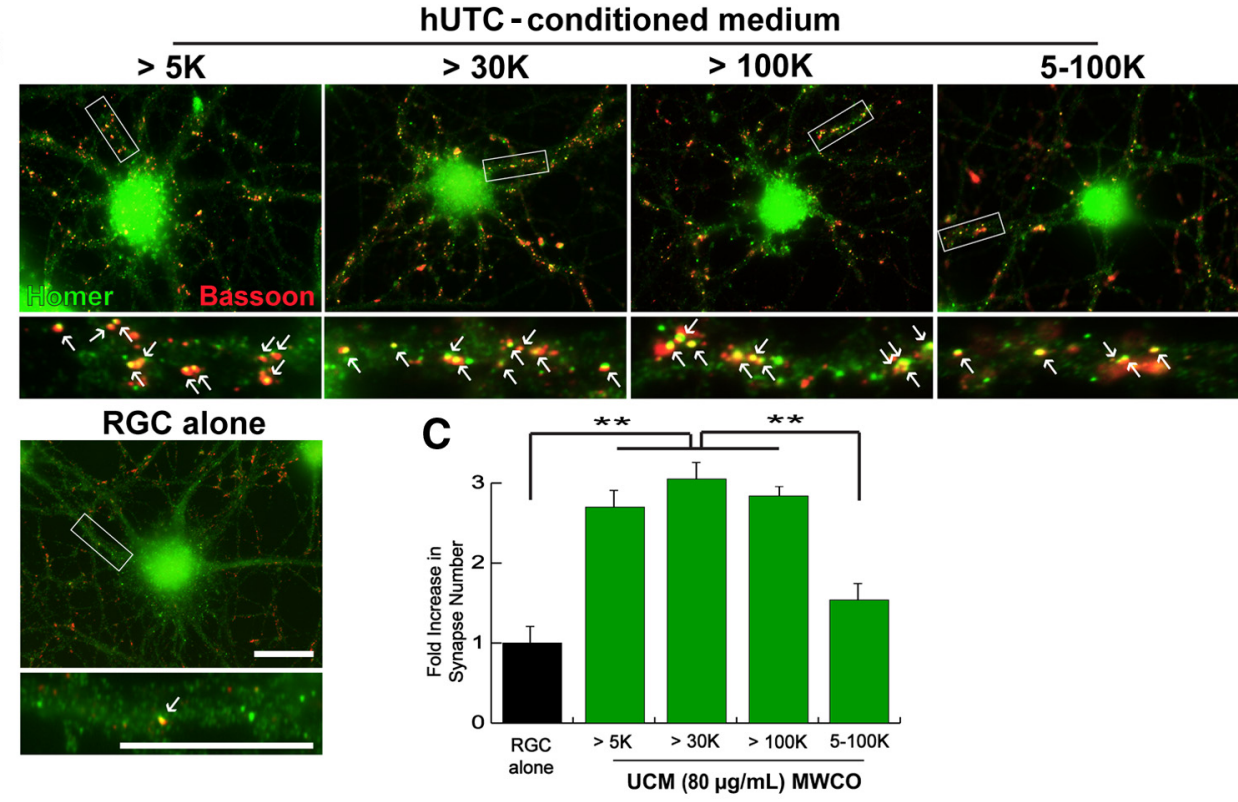

D RGC alone
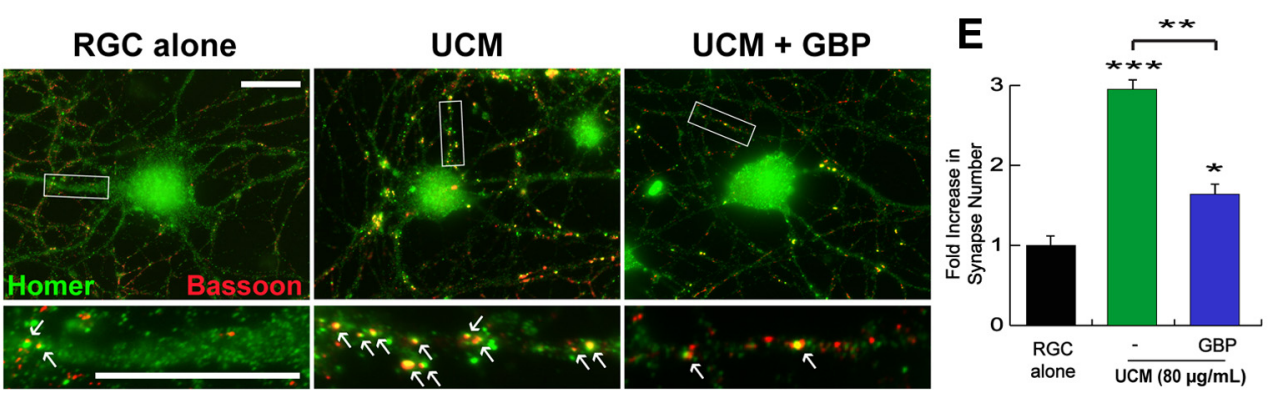

Figure 7. Characterization of the synaptogenic factors in the UCM. A, Schematic representation of experimental design. Purified RGCS were treated with UCM for $6 \mathrm{~d}$ that was fractionated by using centrifugal concentrators with different molecular weight cutoffs. Synapse numbers were then quantified as described before. $\boldsymbol{B}$, Representative RGC images showing the colocalized synaptic puncta (presynaptic: Bassoon [red]; postsynaptic: Homer [green]). Bottom, White boxes are shown in higher magnification. White arrows indicate colocalized synaptic puncta. Scale bars, $20 \mu \mathrm{m}$. C, Quantification of fold increase in synapse number. Fold increase is calculated by normalizing the number of colocalized synaptic puncta/cell to the values obtained in RGC alone condition ( $n=30-44$ cells/condition). $\boldsymbol{D}$, Representative RGC images showing the colocalized synaptic puncta (white arrows, presynaptic: Bassoon [red]; postsynaptic: Homer [green]) in RGCs treated with UCM in the presence or absence of GBP (32 $\mu \mathrm{M})$. Scale bar, $20 \mu \mathrm{m}$. E, Quantification of fold increase in synapse number normalized to RGC alone condition ( $n=24$ or 25 cells/condition). UCM-induced synaptogenesis is significantly inhibited by GBP. Data are mean \pm SEM. ${ }^{* * *} p<0.0001$. ${ }^{* *} p<0.001 .{ }^{*} p<0.05$.

DIV (Fig. 5A, left, $B$ ). Addition of growth factors, such as BDNF or CNTF, only in the presence of forskolin, significantly increases RGC survival (Meyer-Franke et al., 1995). We found that addition of UCM into minimal media strongly stimulated RGC survival in a concentration-dependent manner (Fig. 5A, right, $B$, one-way ANOVA, $p<0.0001$ ). Interestingly, ACM did not promote RGC survival at the same concentrations (Fig. $5 B$ ).

Previous studies demonstrated that neurotrophic factors, such as BDNF, CNTF, and IGF-1, support RGC survival albeit only when forskolin is present (Meyer-Franke et al., 1995). Forskolin in the culture media increases cAMP levels in neurons mimicking ongoing neuronal activity, which is critical for survival of CNS neurons (Meyer-Franke et al., 1995). In line with these earlier findings, we found that the survival-promoting activity of UCM is only functional in the presence of forskolin in the minimal medium (Fig. 5C, one-way ANOVA, $p<0.0001$ ). To- gether, these results demonstrate that UCM strongly stimulate RGC survival. At lower concentrations ( $40 \mu \mathrm{g} / \mathrm{ml})$, the survival effect of UCM is additive to that of BDNF or CNTF (Fig. 5D, E, each pair Student's $t$ test, $p<0.0001$ ), suggesting that neurotrophic agents other than these two well-characterized growth factors may be provided by hUTCs.

Atrophy of neuronal processes is a universal event in many neurological disorders; therefore, providing factors that can trigger neurite outgrowth can provide therapeutic effects in these diseases. Thus, we next tested whether hUTC-secreted factors can support neurite outgrowth. To do so, we supplemented RGC growth media with UCM at the time of plating. RGCs were plated at low density and were cultured for $24 \mathrm{~h}$ before they were assayed for neurite outgrowth (for details, see Materials and Methods). Our quantitative analysis showed that UCM contains factors that promote neurite outgrowth and elaboration (Fig. 6A-C). Similar 


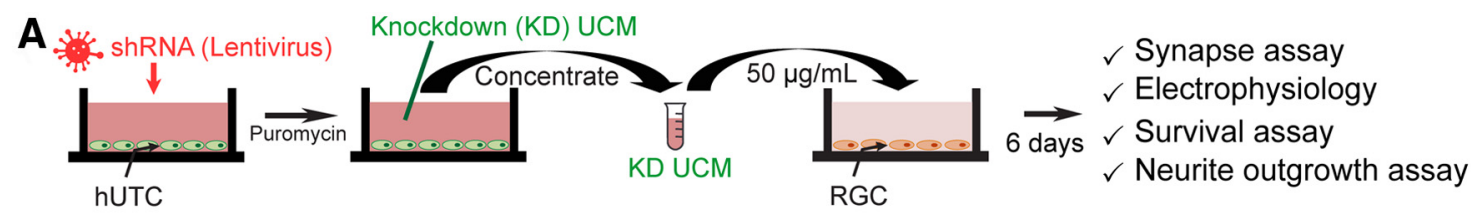

B

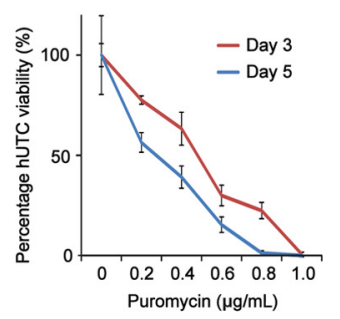

C

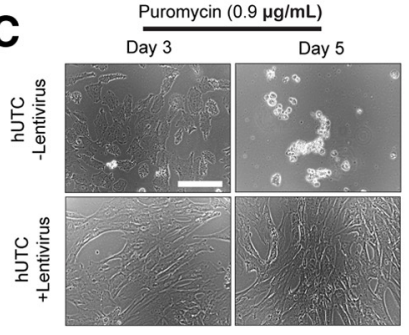

D

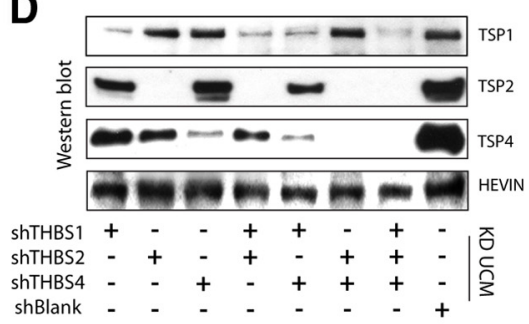

Figure 8. Production of TSP-silenced hUTC-conditioned media. A, Schematic presentation of experimental design for TSP-knockdown experiments (Figs. 8, 9, 10, 11, 12, 13-14). TSP1, TSP2, and TSP4 expression was silenced by lentiviral shRNA transductions of hUTCs and knockdown (KD) UCM is harvested. RGCs were treated with KD UCM for 6 d. UCM's effects on synapse formation (synapse assay), synaptic function (electrophysiology), neuronal survival (survival assay), and neurite outgrowth (outgrowth assay) were determined. B, Kill curve of hUTCs without lentiviral transduction in the presence of various puromycin concentrations at days 3 and 5 ( $n=3$ microscopic field/per condition). $C$, Representative images of hUTCs with and without lentivirus infection in the presence of puromycin $(0.9 \mu \mathrm{g} / \mathrm{ml})$ at days 3 and 5 . Scale bar, $50 \mu \mathrm{m}$. D. Western blot confirmation of TSP1, TSP2, and TSP4 knockdown using lentiviral shRNA transductions. An unrelated hUTC-secreted protein called HEVIN was used as loading control.

to UCM, ACM also promoted neurite outgrowth (Fig. 6A-C, ANCOVA, $p<0.0001$; Fig. $6 C$, one-way ANOVA, $p<0.0001$ ), although UCM in general was more efficient in inducing overall elaboration and branching (Fig. 6D,E, one-way ANOVA, $p<$ $0.0001)$. Sholl analysis showed that UCM robustly increases neuronal complexity, compared with RGCs cultured alone (Fig. 6B). These results show that UCM contain factors that support neurite outgrowth in addition to the synaptogenic and neurotropic effects. Together, our findings strongly suggest that hUTCs can bolster neuronal health and provide structural and functional regeneration via these three mechanisms.

\section{hUTC-secreted synaptogenic factors are $>100 \mathrm{kDa}$ and are blocked by GBP}

To identify the synaptogenic factors secreted by hUTCs, we first fractionated UCM using different molecular weight cutoff size exclusion columns (Fig. 7A). We found that the synaptogenic effect of UCM is concentrated within the fraction that is larger than $100 \mathrm{kDa}$ (Fig. 7 B, C, one-way ANOVA, $p<0.001$ ).

It was previously shown that astrocytes secrete synaptogenic TSP family proteins, which are large oligomeric extracellular matrix proteins with sizes ranging from 400 to $450 \mathrm{kDa}$. All TSPs (TSP1-TSP5) can induce synaptogenesis (Christopherson et al., 2005; Eroglu et al., 2009), and TSP1 is known to also induce neurite outgrowth (Neugebauer et al., 1991; DeFreitas et al., 1995). Analyses of UCM by antibodies specific to TSPs revealed that hUTCs secrete TSP1, TSP2, and TSP4 (data not shown). To test whether TSPs are involved in UCM-induced synapse formation, we used a pharmacological agent, GBP $(32 \mu \mathrm{M})$, which is a known blocker of TSP-induced synaptogenesis (Eroglu et al., 2009). GBP binds to the synaptogenic TSP receptor, the calcium channel subunit $\alpha 2 \delta$-1, and inhibits the interaction between TSP and $\alpha 2 \delta-1$ (Eroglu et al., 2009). In agreement with a role for TSPs in UCM-induced synapse formation, addition of GBP during UCM treatment diminished the majority of the synaptogenic activity of UCM (Fig. 7 D, E, one-way ANOVA, $p<0.0001$ ). These results suggest that TSP family proteins are the major synaptogenic factors secreted by hUTCs.
TSPs are necessary for the synaptogenic activity of UCM

To test whether hUTC-secreted TSPs are required for the synaptogenic effect of UCM, we silenced the expression of TSP1, TSP2, and TSP 4 in hUTCs by lentivirus-mediated shRNA transduction (Fig. 8A-D). Using isoform-specific shRNAs, TSPs were knocked down individually or in combination. Only the hUTCs transduced with shRNA-containing lentivirus were cultured to produce conditioned medium using puromycin selection (Fig. $8 B, C)$. Specific knockdown of each TSP by the corresponding shRNA was confirmed by Western blotting (Fig. $8 D$ ). UCM produced from the lentiviral transduction of same parent plasmid vector without shRNAs (KD-CTR) or with lentivirus containing scrambled TSP1, TSP2, and TSP4 shRNAs (SCR-CTR) were used as controls. UCM were produced from lentivirus-infected hUTCs and applied to RGCs to identify the effects of TSP knockdown (Fig. 8A). Quantification of synapse numbers and synapse density in RGCs revealed that all three TSPs (TSP1, TSP2, and TSP4) contributed to the synaptogenic function of UCM (Fig. $9 A-D)$. Knockdown of all three TSPs (TSP1+2+4-KD) completely abolished the ability of UCM to induce synapse formation compared with UCM made from SCR-CTR transduced UTC (Fig. 9A, $B$, one-way ANOVA, $p<0.0001$ ). To test whether all three TSPs are required for synaptogenesis, we silenced TSPs individually or in dual combinations (Fig. 9C). Individual knockdown of TSPs significantly decreased the number of synapses and synaptic density compared with KD-CTR UCM (Fig. 9A, C,D, one-way ANOVA, $p<0.0001)$. These results indicate that TSPs are required for the synaptogenic activity of UCM.

To determine how TSPs contributed to the effect of UCM on synaptic activity, we next recorded mEPSCs from RGCs that were treated with ACM (positive control), SCR-CTR, or TSP $1+2+4-K D$ UCM. We found that silencing of TSP expression greatly diminished the UCM-induced increase in the frequency of synaptic events (Fig. 10A-C, Kruskal-Wallis test, $p<$ 0.0001; Fig. 10C, one-way ANOVA, $p<0.0001$ ). This result is in agreement with our findings that TSP1, TSP2, and TSP4 are required for the ability of UCM to induce synaptogenesis (Fig. 9). Together, these findings show that silencing of TSP1, TSP2, and TSP4 in hUTCs eliminates the ability of these cells to induce an 

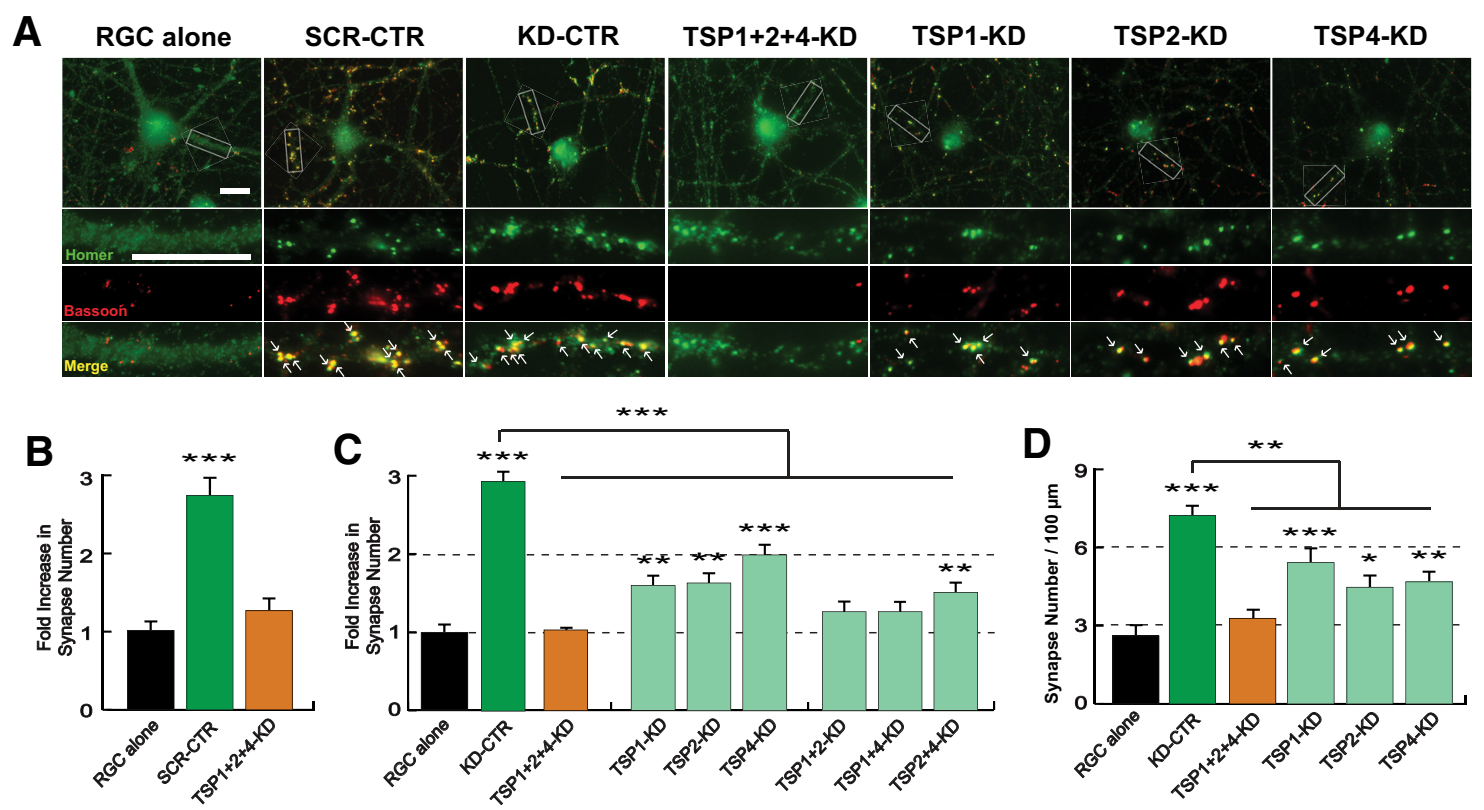

Figure 9. TSP1, TSP2, and TSP4 are required for hUTC-induced synaptogenesis. A, Representative images of RGCs showing the colocalized synaptic puncta (presynaptic: Bassoon [red]; postsynaptic: Homer [green]) demonstrate that the synaptogenic activity of UCM is lost when TSP1 + 2+4-KD UCM is used. Bottom, White boxes are shown in higher magnification. White arrows indicate colocalized synaptic puncta. Scale bar, $20 \mu \mathrm{m} . \boldsymbol{B}$, Fold increase in synapse numbers in RGC-treated scrambled control UCM (SCR-CTR) and TSP-KD UCM normalized to the RGC alone condition ( $n=30$ cells/condition). C, Fold increase in synapse numbers in RGCs treated with various TSP-KD UCM normalized to RGC alone condition ( $n=76-81$ cells/condition). $\boldsymbol{D}$, Quantification of the changes in synaptic density (number of colocalized synaptic puncta/neurite length) after treatment with various TSP-KD UCM. Knockdown of each TSP leads to a partial but significant reduction in the ability of UCM to increase synaptic density ( $n=24-26$ cells/condition). Data are mean \pm SEM. ${ }^{* * *} p<0.0001 .{ }^{* *} p<0.001 .{ }^{*} p<0.05$.

increase in synapse numbers, which is demonstrated by the loss of colocalized synaptic puncta (Fig. 9) and the reduction in the frequency of synaptic events (Fig. 10A,B).

Supplementing the TSP $1+2+4-$ KD UCM with pure TSP 1 , TSP2, and TSP4 (150 ng/ml each) fully restored the synaptogenic effect of the TSP $1+2+4$-KD UCM (Fig. $11 A, B$, one-way ANOVA, $p<0.0001)$. This result confirms that silencing of TSP expression in hUTCs is the cause of the loss of synaptogenic effect of these cells. Furthermore, in agreement with TSPs being the synaptogenic factors in the UCM, adding pure TSPs into KD-CTR UCM did not further increase the synapse numbers (Fig. 11C). Together, our results show that TSP1, TSP2, and TSP4 are the major factors in UCM that drive the increase in synapse numbers.

\section{hUTC-secreted TSPs promote neurite outgrowth}

It was previously shown that TSP1 promotes neurite outgrowth (Neugebauer et al., 1991; DeFreitas et al., 1995). Thus, we next tested whether TSPs contribute to the neurite outgrowth-promoting effect of hUTCs. Silencing TSP expression abolished neurite outgrowth effects of UCM (Fig. 12A-E, ANCOVA, $p<0.0001)$. Single knockdowns of TSP1, TSP2, or TSP4 were all enough to completely abolish the neurite outgrowth-promoting effects of UCM (Fig. 12F, one-way ANOVA, $p<0.0001)$, including the effects on the number of processes and the number of branches (Fig. 12G,H). Interestingly, KD of TSP1 or TSP2, but not TSP4, alone led to a minor but significant inhibition of neurite outgrowth by UCM compared RGCs cultured alone (Fig. 12F, marked by \#, one-way ANOVA, $p<0.0001)$. This result suggests that UCM contains factors that inhibit neurite outgrowth and the negative effects of these factors can be overcome by TSP1 and TSP2.

Supplementing the TSP $1+2+4-\mathrm{KD}$ UCM with pure TSPs $(150 \mathrm{ng} / \mathrm{ml})$ rescued the neurite outgrowth-promoting func- tion of the UCM (Fig. 13A-C). Adding back TSP2 or TSP4 alone to the TSP $1+2+4-\mathrm{KD}$ UCM fully recovered the neurite outgrowth-stimulating function of the UCM (Fig. 13C, each pair Student's $t$ test, $p<0.0001)$. However, adding TSP 1 back did not rescue the outgrowth effect of TSP $1+2+4-\mathrm{KD}$ UCM (Fig. 13C). These results show that TSP2 and TSP4 are more active in promoting neurite outgrowth than TSP1 in the full complement of the UCM. Together, these results show that TSPs are required for the neurite outgrowth-promoting function of UCM in vitro.

\section{hUTCs induce neurite outgrowth under growth-inhibiting conditions}

Upon CNS injury, CSPGs are overproduced by reactive glia, and myelin proteins, such as Nogo-A, are released from degenerating nerve fibers. These proteins inhibit axon regeneration (Niederöst et al., 2002; Silver and Miller, 2004; Usher et al., 2010; Walker et al., 2012), impeding neuronal repair after injury. Therefore, we next tested whether hUTCs could promote neurite outgrowth under conditions that inhibit growth. To do so, we modified the RGC neurite outgrowth assay by coating the coverslips with CSPG or Nogo-A (Fig. 14A, B). CSPG significantly hindered neurite outgrowth starting at $0.05 \mu \mathrm{g} / \mathrm{cm}^{2}$ and completely blocked growth at $0.2 \mu \mathrm{g} / \mathrm{cm}^{2}$ or higher concentrations (Fig. 14A, Student's $t$ test, $p<0.05)$ Similarly, Nogo-A blocked neurite outgrowth in RGCs starting at $1 \mu \mathrm{g} / \mathrm{cm}^{2}$ with $>50 \%$ of neurite growth inhibited at $2 \mu \mathrm{g} / \mathrm{cm}^{2}$ (Fig. $14 B$, Student's $t$ test, $p<$ $0.05)$. Interestingly, hUCM transduced with lentiviruses that encode scrambled shRNAs (SCR-CTR UCM) induced neurite outgrowth in RGCs that were plated onto coverslips with $0.05 \mu \mathrm{g} /$ $\mathrm{cm}^{2}$ CSPG or $1 \mu \mathrm{g} / \mathrm{cm}^{2}$ Nogo-A (Fig. $14 A, B$, Student's $t$ test, $p<$ $0.0001)$. These results show that hUCM is capable of inducing neurite outgrowth, even under growth-inhibiting conditions. However, SCR-CTR UCM was not able to trigger significant neu- 
A RGC alone

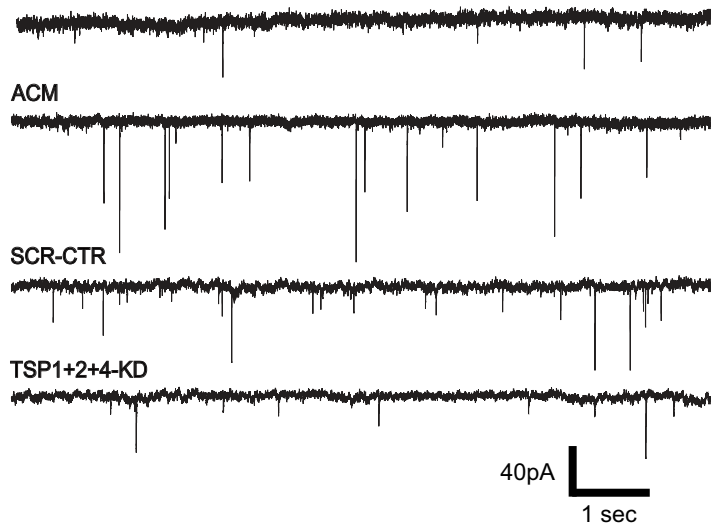

B

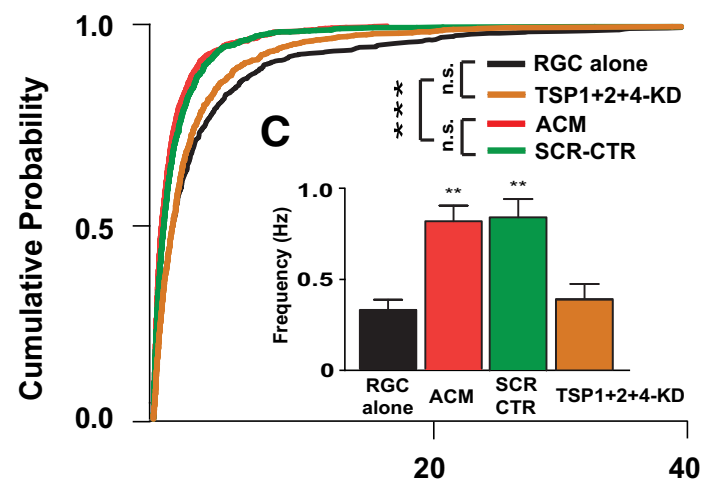

D

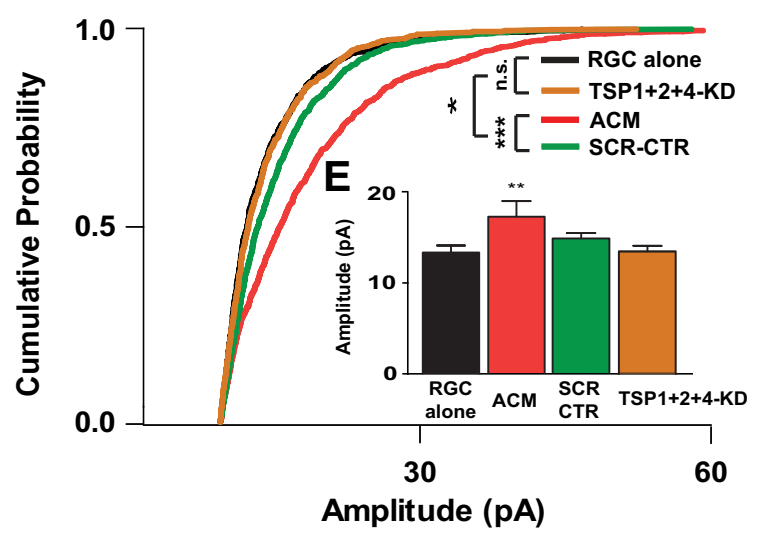

Figure 10. TSP1, TSP2, and TSP4 are required for hUTC-induced increase in synaptic function. $\boldsymbol{A}$, Example traces from whole-cell patch-clamp recordings showing mEPSCs from RGCS treated with ACM (positive control), SCR-CTR, TSP1+2+4-KD UCM, or RGCs cultured alone (negative control). Silencing of TSPs in UCM (TSP1+2+4-KD) abolishes both the frequency ( $\boldsymbol{B}$, $\boldsymbol{C}$ ) and amplitude $(\boldsymbol{D}, \boldsymbol{E})$ increases that were achieved by SCR-CTR. Quantified data are demonstrated as cumulative probability plots $(\boldsymbol{B}, \boldsymbol{D})$ and bar graphs of mean values $(\boldsymbol{C}, \boldsymbol{E}) . n=15$ cells/condition. Data are mean \pm SEM. ${ }^{* * *} p<0.0001$. ${ }^{* *} p<0.001 .{ }^{*} p<0.05$. n.s., Not significant.

rite outgrowth at high CSPG $\left(>0.2 \mu \mathrm{g} / \mathrm{cm}^{2}\right)$ and Nogo-A (2 $\mu \mathrm{g} / \mathrm{cm}^{2}$ ) concentrations (Fig. $14 A, B$, Student's $t$ test, not significant).

Unlike SCR-CTR UCM, TSP $1+2+4-\mathrm{KD}$ UCM did not trigger neurite outgrowth when $0.05 \mu \mathrm{g} / \mathrm{cm}^{2}$ CSPG (Fig. $14 C, E$ ) or $1 \mu \mathrm{g} / \mathrm{cm}^{2}$ Nogo-A (Fig. $14 D, F$ ) was present, indicating that TSPs are centrally important for the neurite outgrowth-promoting effects of hUCM under growth- inhibiting conditions. Addition of purified TSP2 or TSP4 alone or all three TSPs together rescued the ability of TSP $1+2+4-\mathrm{KD}$ UCM to induce neurite outgrowth in the presence of CSPG or Nogo-A (Fig. 14C-F, each pair Student's $t$ test, $p<0.05$ ). These results show that TSPs, particularly TSP2 and TSP4, are responsible for the growth-stimulating effects of hUCM in the presence of CSPG or Nogo-A.

Myelin debris that is generated by CNS injury also sheds high levels of the myelin protein MBP (Liu et al., 2006; Stapulionis et al., 2008). To determine whether MBP had neurite outgrowth-inhibiting effects on CNS neurons, we performed the RGC outgrowth assay in the presence of $10 \mu \mathrm{g} / \mathrm{ml}$ soluble MBP. We chose this MBP concentration because a previous study showed that MBP induces neurotoxicity at concentrations $>10 \mu \mathrm{g} / \mathrm{ml}$ (Zhang et al., 2014). We found that MBP at $10 \mu \mathrm{g} / \mathrm{ml}$ leads to a mild, but significant, loss of neurite outgrowth in RGCs (Fig. 14J, $14 \pm 0.07 \%$ reduction in outgrowth compared with RGCs culture under normal growth media conditions; Student's $t$ test, $p<0.05)$. SCR-CTR UCM still induced significant neurite outgrowth in the presence of MBP, and this effect of the UCM was lost when TSPs were silenced (i.e., TSP1+2+4-KD UCM; Fig. 14G,I). Interestingly, only the addition of pure TSP 2 back into the TSP $1+2+4-\mathrm{KD}$ UCM rescued the outgrowth-promoting effect. This result shows that, in the presence of MBP, TSP2 can still mediate neurite outgrowth. Together, these results show that, under growthinhibiting conditions, hUTC-secreted TSPs, TSP2, and TSP4 mediate neurite outgrowth. In agreement with this, we found that the addition of pure TSPs to the growth media is sufficient to induce RGC neurite outgrowth in the presence of CSPG, Nogo-A, or MBP (Fig. 14H,J).

TSPs do not mediate the survival-promoting effects of hUTCs To determine the effect of hUTC-secreted TSPs on RGC survival, we next tested the survival-promoting effect of TSP $1+2+4-\mathrm{KD}$ UCM under minimal media conditions. We found that knockdown of TSP2 or TSP4 or all three TSPs, but not TSP1 alone, results in a small but significant decrease in the survivalpromoting activity of the UCM (Fig. 15 A, B, each pair Student's $t$ test, $p<0.001)$. Supplementing the TSP $1+2+4-$ KD UCM with pure TSPs either individually or all together did not rescue the survival-promoting function of the UCM (Fig. 15A, C, each pair Student's $t$ test, $p<0.001$ ). These results show that TSPs do not account for the major survival-promoting activity of UCM. However, they may affect neuronal survival potentially by altering the expression or function of other neurotrophic factors secreted by hUTCs.

\section{Discussion}

Our results provide novel aspects of hUTC-neuron interactions and reveal potential therapeutic mechanisms provided by hUTC therapy. Here we show that paracrine factors secreted by hUTCs promote excitatory synapse formation, enhance synaptic function, and induce neurite outgrowth in addition to supporting neuronal survival. Synaptic dysfunction and loss, degeneration of neuronal processes, and neuron death are hallmarks of neurological diseases and retinal degenerations. Therefore, hUTC cell therapy may provide protective and regenerative signals to neurons that could prevent the onset and/or progression of neurological disorders.

Numerous studies that investigated the underlying mechanisms of neurodegenerative diseases revealed that synaptic abnormalities precede neuronal death in Huntington's disease 
A TSP1+2+4 KD
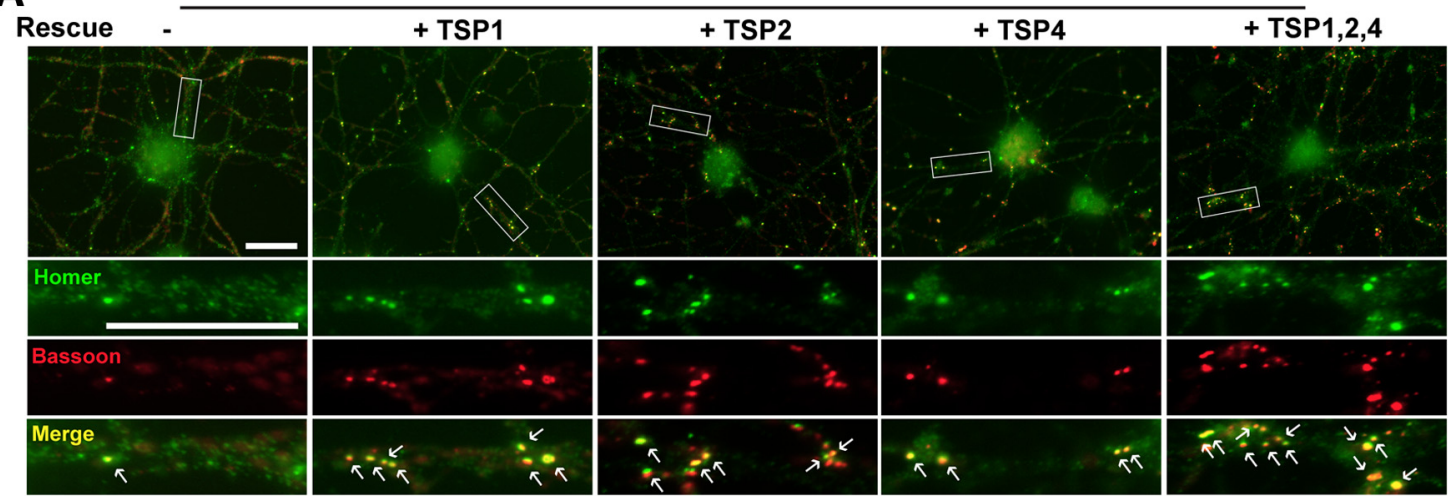

n.s.
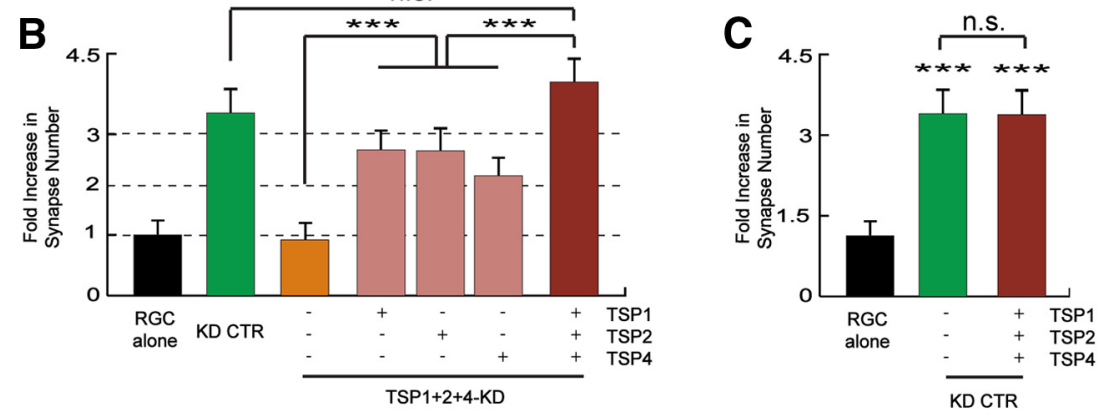

Figure 11. Addition of purified TSPs rescues synaptogenic ability of TSPS KD UCM. A, Representative images of RGCs showing the colocalized synaptic puncta (presynaptic: Bassoon [red]; postsynaptic: Homer [green]) demonstrate that the synaptogenic activity of UCM is lost when TSP1+2+4-KD UCM is used. This loss can be rescued by adding purified TSP1, TSP2, and TSP4 (150 ng/ml each) into the KD UCM. Bottom, White boxes are shown in higher magnification. White arrows indicate colocalized synaptic puncta. Scale bar, $20 \mu \mathrm{m}$. $\boldsymbol{B}$, Fold increase in synapse numbers for RGCs treated with TSP1 $+2+4-K D$ UCM in the presence of purified TSPs normalized to RGC alone condition ( $n=30$ cells/condition). Addition of all three TSPs (TSP1, TSP2, and TSP4) rescues the synaptogenic effects of TSP1 +2+4-KD UCM. C, Quantification of synapses formed between RGCs cultured alone (negative control) or RGCs treated with KD CTR UCM in the presence of purified TSPs ( $n=30$ cells/condition). Addition of purified TSPs to KD CTR UCM does not lead to a further increase in the number of synapses. Data are mean \pm SEM. ${ }^{* * *} p<0.0001$. n.s., Not significant.

(Reiner et al., 1988; Davies et al., 2007; Orth et al., 2010; McKinstry et al., 2014), Alzheimer's disease (Hynd et al., 2004; Abramov et al., 2009), Parkinson's disease (Plowey and Chu, 2011; Luk et al., 2012), and retinal degenerations (Tso et al., 1994; Jones et al., 2003; Cuenca et al., 2005). The progressive loss of synaptic function, leading to the deterioration of the neuroanatomy, is thought to be the main driver of neuron loss (Raff et al., 2002; Milnerwood and Raymond, 2010; Conforti et al., 2014; Neukomm and Freeman, 2014). Therefore, our findings also bring forward the idea that hUTC therapy could be used to preserve synaptic connectivity, repair neuronal anatomy, and sustain neuronal health providing a useful common restorative intervention in neurodegenerative diseases.

\section{hUTCs induce synapse formation and neurite outgrowth by secreting TSPs}

TSPs are important regulators in the development and injurydependent remodeling of the mammalian nervous system (Christopherson et al., 2005; Liauw et al., 2008; Eroglu et al., 2009; Benner et al., 2013). A previous study reported that umbilical cord blood-derived cells secrete TSP 2 that promotes chondrogenic differentiation of bone progenitor cells (Jeong et al., 2013). However, it was not known whether hUTCs, a distinct cell population from the cord blood cells, also produce TSPs. Here, we identified TSP family proteins, TSP1, TSP2, and TSP4, as the critical hUTC-secreted factors that induce excitatory synapse formation. Silencing of TSP expression in hUTCs revealed that each of these TSPs is partially responsible for the synaptogenic effect of the UCM. hUTC-secreted TSP1 and TSP2 appeared to exert a larger portion of the synaptogenic effect of UCM compared with TSP4. However, only the triple knockdown of TSPs is able to eliminate the full synaptogenic effects of hUTCs, revealing that all three subtypes of TSPs, TSP1, TSP2, and TSP4, significantly contribute to this function of hUTCs. These results are in line with our previous findings that showed that all members of the TSP family share the synapse-inducing function, which is mediated by the EGFlike domains, a signature fold that is found in all TSPs (Eroglu et al., 2009).

In addition to their critical role in promoting synapse formation, we found that hUTC-secreted TSPs are required for the neurite outgrowth-stimulating function of the UCM. Silencing the expression of any one of the three TSPs (TSP1, TSP2, or TSP4) in hUTCs led to the complete loss of the neurite outgrowth-stimulating function of UCM (Fig. 12). Moreover, we found that hUTC-secreted TSPs, particularly TSP2 and TSP4, are able to induce significant neurite outgrowth, even in the presence of growth-inhibiting factors, such as CSPG, Nogo-A, and MBP (Fig. 14). The synaptogenic and neurite-outgrowth-promoting effects of TSPs may be performed through different pathways. Indeed, it has been shown that different domains on TSPs interact with a milieu of neuronal surface receptors to mediate many different functions (Risher and Eroglu, 2012).

Together, our results provide an important mechanistic understanding on how hUTCs may be therapeutic. Catastrophic loss of neuronal processes (both axons and dendrites) and their inability to regrow are common occurrences in many 
A RGC alone
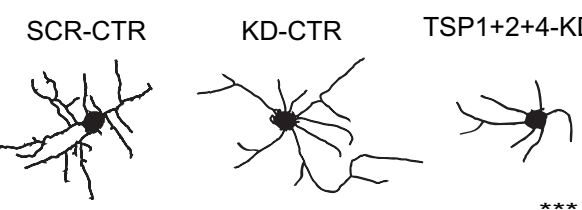

TSP1-KD

TSP2-KD

TSP4-KD
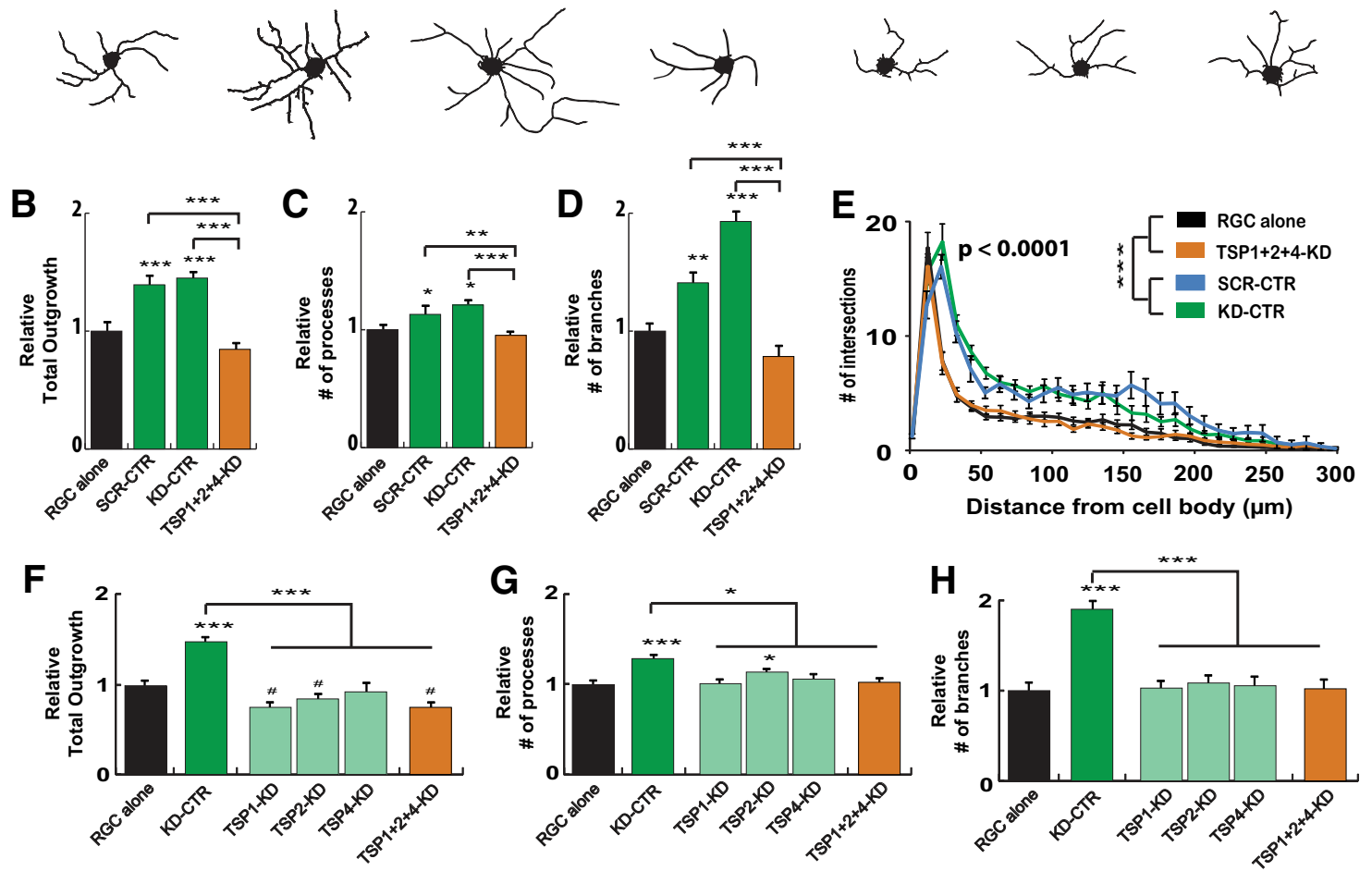

Figure 12. Silencing of TSP expression in hUTCs abolishes UCM-induced neurite outgrowth. $\boldsymbol{A}$, Representative skeletonized traces of RGCS treated with SCR-CTR, KD-CTR, or TSPs KD UCM compared with RGC alone (negative control). Scale bar, $100 \mu \mathrm{m}$. UCM prepared from hUTCs in which TSP expression was silenced (TSP1+2+4-KD UCM) resulted in decreased (B) length, $(\boldsymbol{C})$ processes, and (D) branches of total neurite outgrowth compared with both controls, SCR-CTR, and KD-CTR ( $n=40-48$ cells/condition). $\boldsymbol{E}$, Silencing of TSPs in hUTCs resulted in a UCM decreased complexity shown by Sholl analysis $(n=25$ cells/condition). Silencing of individual TSPs in hUTCs also resulted in decreased $(\boldsymbol{F})$ length, $(\boldsymbol{G})$ processes, and $(\boldsymbol{H})$ branches of total neurite outgrowth ( $n=120-169$ cells/condition). "Significant reduction in total outgrowth compared with RGC alone condition $(p<0.05)$. Data are mean \pm SEM. ${ }^{* * *} p<0.0001 .{ }^{* *} p<0.001 .{ }^{*} p<0.05$.

A

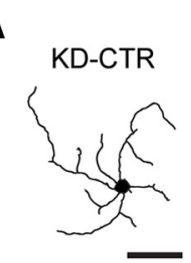

B

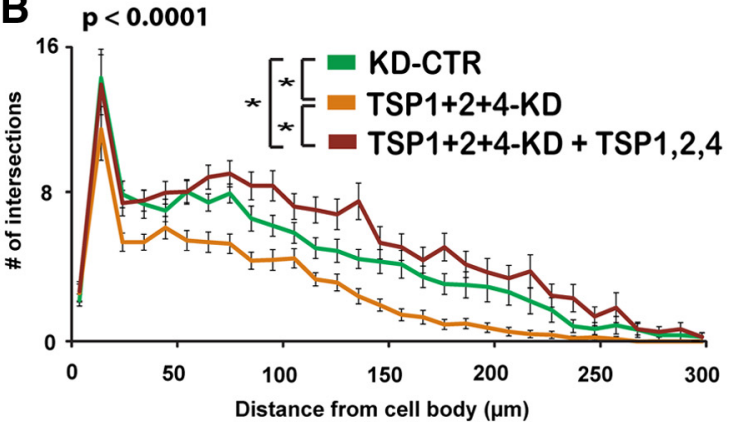

$\mathrm{TSP} 1+2+4-\mathrm{KD}$
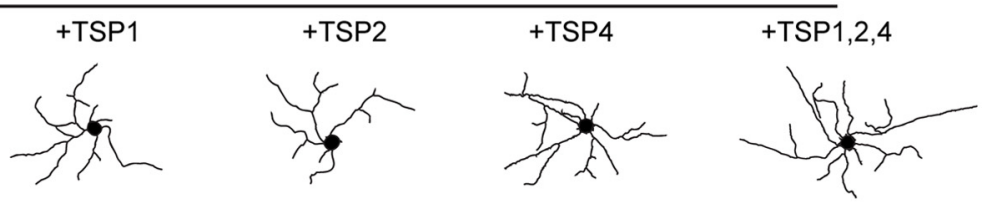

C

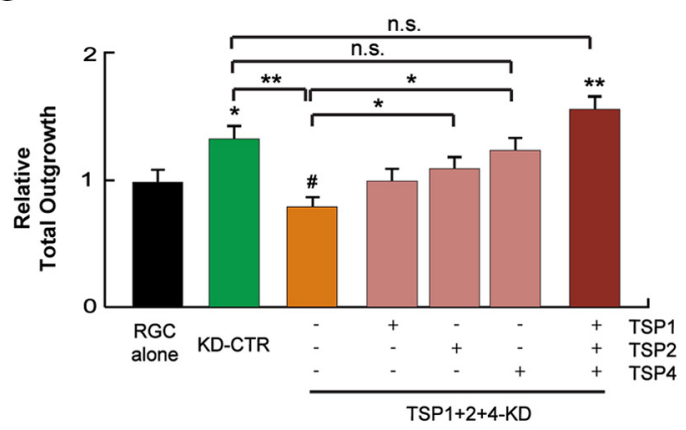

Figure 13. TSPs are necessary for UCM-induced neurite outgrowth. $\boldsymbol{A}$, Representative skeletonized traces of RGCs treated with KD-CTR or TSP1+2+4-KD UCM in the presence of purified TSPs. Scale bar, $100 \mu \mathrm{m}$. Addition of purified TSPs into TSP1+2+4-KD UCM restored function of UCM to enhance $(\boldsymbol{B})$ complexity $(n=30$ cells/condition) and $(\boldsymbol{C})$ total neurite growth $\left(n=29-33\right.$ cells/condition). "Significant reduction in total outgrowth compared with RGC alone condition $(p<0.05)$. ${ }^{* *} p<0.001$. ${ }^{*} p<0.05$. n.s., Not significant.

disorders, including neurodegenerative diseases (Raff et al., 2002; Conforti et al., 2014; Neukomm and Freeman, 2014). Our results indicate that hUTCs, via secretion of TSPs, support the health of existing neurites and stimulate the re- generation of new processes. Concurrently, these new neurites could provide sites for regenerative synapse formation triggered by hUTC-secreted TSPs, leading to reestablishment of synaptic connectivity. 
A

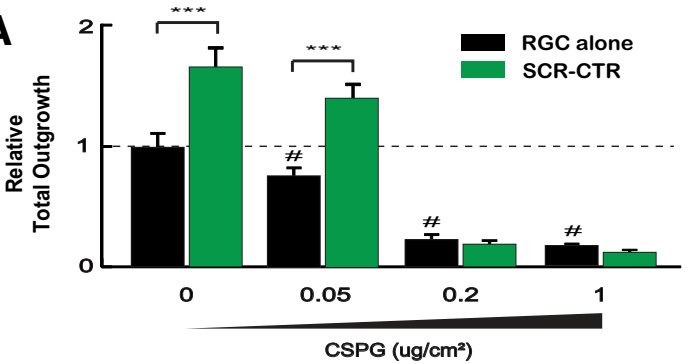

\section{C}

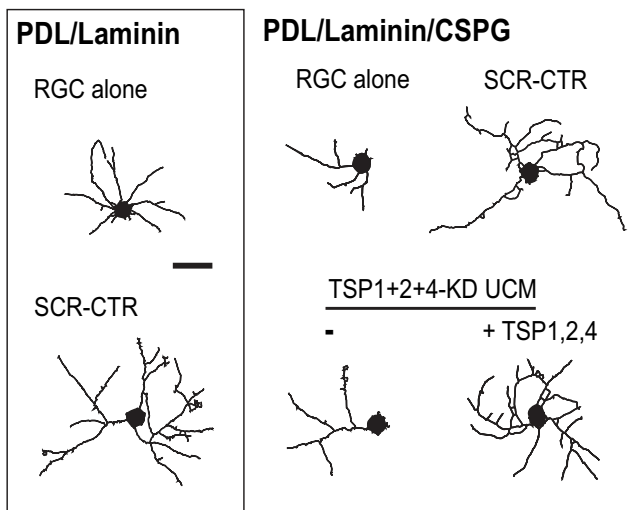

E CSPG $\left(0.05 \mathrm{ug} / \mathrm{cm}^{2}\right)$

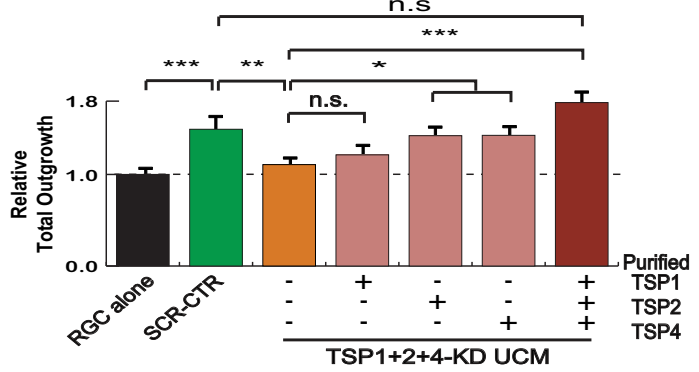

G MBP (10 ug/mL)

RGC alone

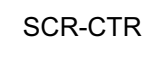

TSP1+2+4-KD UCM
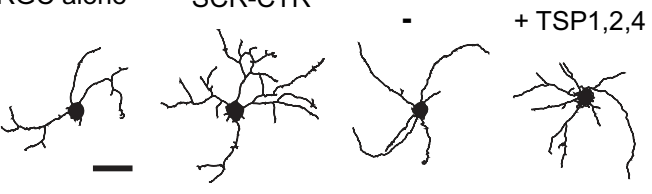

MBP (10 ug/mL)

I

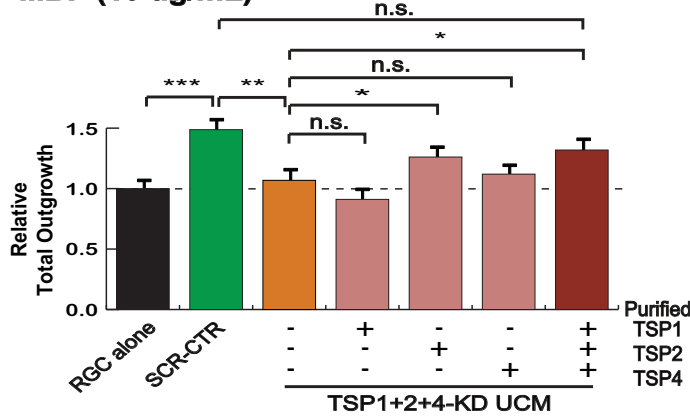

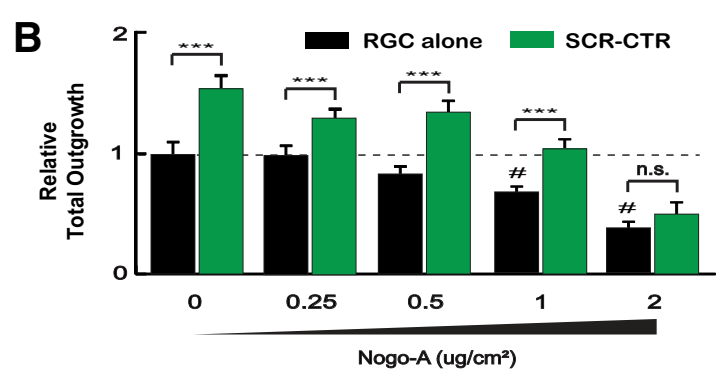

D PDL/Laminin/Nogo-A

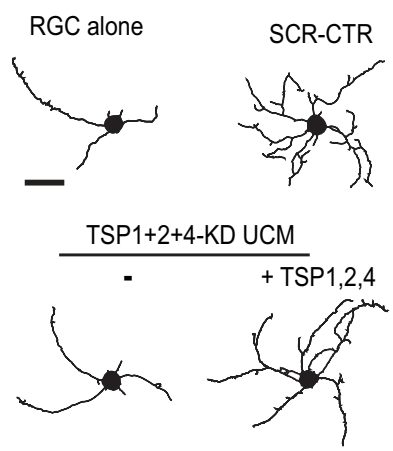

F Nogo-A (1 ug/cm²)

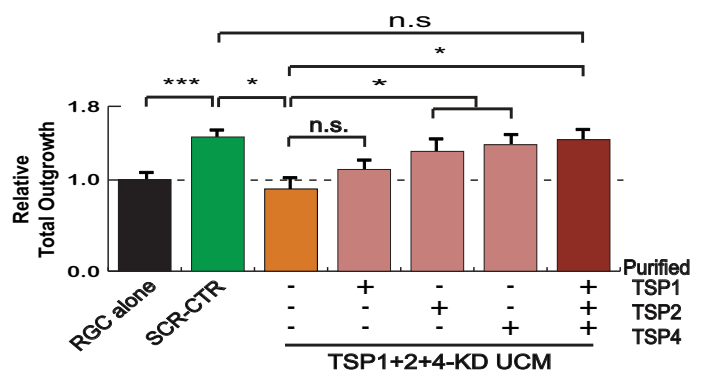

H

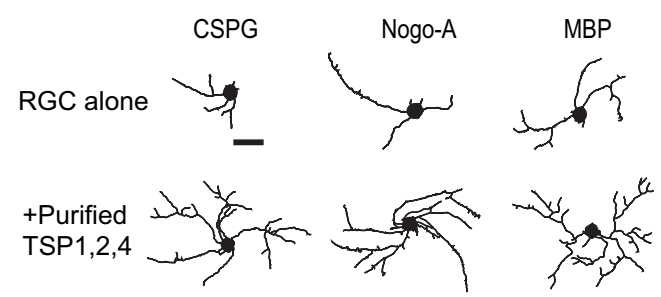

J

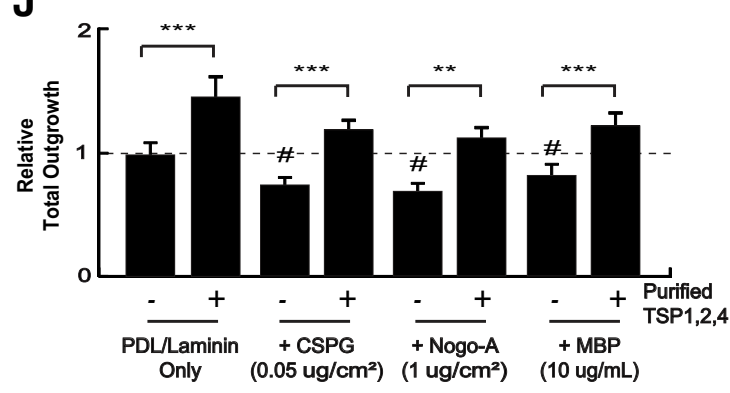

Figure 14. hUTC-secreted TSPs induce neurite outgrowth in the presence of CSPG, Nogo-A, or MBP. Quantification of total neurite outgrowth on coverslips coated with increasing concentrations of $(\boldsymbol{A})$ CSPG ( $n=45-79$ cells/condition) or (B) Nogo-A ( $n=30-37$ cells/condition). Graphs are presented as the fold increase normalized to the value of the outgrowth of RGCs plated on coverslips that do not contain CSPG or Nogo-A. Representative skeletonized traces of RGCs treated with SCR-CTR, TSPs KD UCM, and purified TSPs plated onto (C) CSPG $\left(0.05 \mu \mathrm{g} / \mathrm{cm}^{2}\right)$ or $(D)$ Nogo-A $\left(1 \mu \mathrm{g} / \mathrm{cm}^{2}\right)$ coated coverslips. Scale bar, $100 \mu \mathrm{m}$. Quantification of total neurite outgrowth of RGCs plated onto $(\boldsymbol{E})$ CSPG $\left(0.05 \mu \mathrm{g} / \mathrm{cm}^{2}, n=62-103\right.$ cells $\left./ \mathrm{condition}\right)$ or $(\boldsymbol{F}) \mathrm{Nogo}-\mathrm{A}\left(1 \mu \mathrm{g} / \mathrm{cm}^{2}, n=25-29\right.$ cells/condition) coated coverslips. Graphs are presented as the fold increase normalized to the value of the RGCs cultured with growth media only (RGC alone) under each culture condition. $\mathbf{G}$, Representative skeletonized traces of RGCS treated with SCR-CTR or TSP1+2+4-KD UCM alone or supplemented with purified TSPs in the presence (Figure legend continues.) 


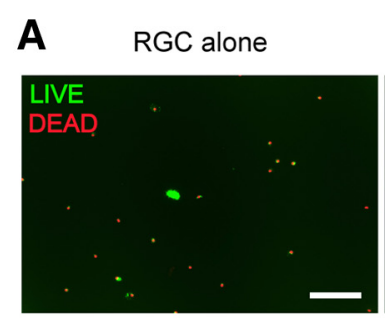

B

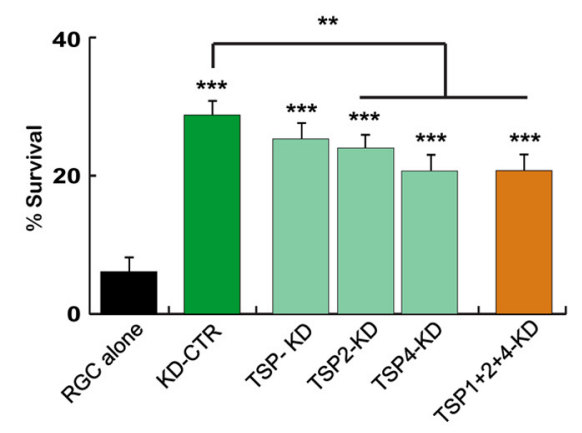

KD-CTR

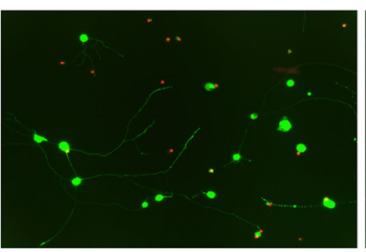

TSP1+2+4-KD

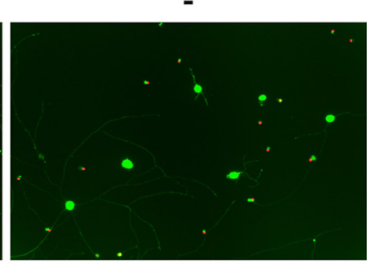

C

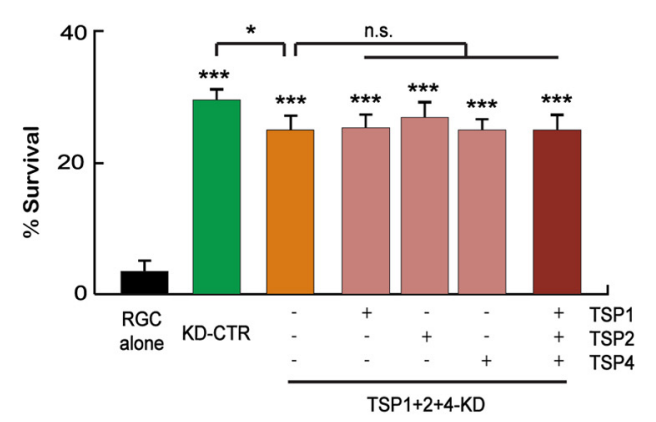

Figure 15. TSPs are not major effectors of UCM-induced cell survival. $\boldsymbol{A}$, Representative images of RGCs treated with survival assay reagents: Calcein-AM for live cells (green) and ethidium homodimer-1 for dead cells (red). Scale bar, $100 \mu \mathrm{m}$. B, Quantification of the percentage survival in RGCs treated with various TSP-KD UCM conditions ( $n=30$ microscopic field/condition). Silencing of TSP2 or TSP4 or all three TSPs resulted in a minor reduction in the survival-promoting effect of UCM. C, Addition of pure TSPs into TSP1+2+4-KD UCM did not restore the full survival effects of KD-UCM ( $n=20$ microscopic field/condition). Data are mean \pm SEM. ${ }^{* *} p<0.0001 .{ }^{* *} p<0.001 .{ }^{*} p<0.05$. n.S., Not significant.

\section{hUTCs enhance synaptic function}

Previous studies on the role of astrocytes in synapse formation showed that TSP1 and TSP2 are the necessary and sufficient factors in ACM that stimulate a strong increase in synapse number (Christopherson et al., 2005). However, these studies also revealed that the TSP-induced synapses are postsynaptically inactive due to the lack of AMPA-type glutamate receptors on the postsynaptic side (Christopherson et al., 2005). Astrocytes secrete other signals, including the Glypican $(\mathrm{Gpc})$ family proteins Gpc-4 and Gpc-6, which trigger insertion of AMPA receptors to synapses promoting formation of postsynaptically functional synapses (Allen et al., 2012). Here we found that the synapses formed, either by coculture with hUTCs or by UCM treatment, are postsynaptically active, similar to the astrocyte-induced synapses. These results indicate that, in addition to TSPs, which increase the synapse number, hUTCs secrete factors that stimulate functional maturation of the postsynaptic activity. This result indicates that hUTCs secrete factors other than TSPs that enhance postsynaptic activity, potentially through a similar mechanism to astrocytes.

\section{hUTCs support neuronal survival through factors other than TSPs}

Using the purified RGC culture system, we took advantage of the well-defined serum-free media conditions to explore the potential

\section{$\leftarrow$}

(Figure legend continued.) of MBP (10 $\mu \mathrm{g} / \mathrm{ml})$. Scale bar, $100 \mu \mathrm{m}$. H, Representative skeletonized traces of RGCS treated with purified TSPs in the presence of growth-inhibiting substances. Scale bar, $100 \mu \mathrm{m}$. I, Quantification of total neurite outgrowth demonstrated enhancement of neurite outgrowth activity of UCM-secreted TSP2 in the presence of MBP ( $n=$ $40-54$ cells/condition). Graph is presented as the fold increase normalized to the value of the RGC alone condition. J, Treatment of RGCs with purified TSPs is able to induce significant outgrowth in the presence of CSPG, Nogo-A, or MBP ( $n=41-54$ cells/condition). Data are mean \pm SEM. ${ }^{* * *} p<0.0001 .{ }^{* *} p<0.001 .{ }^{*} p<0.05$. n.s., Not significant. "Significant reduction in total outgrowth compared with $\mathrm{RGC}$ alone condition $(p<0.05)$. neurotrophic effects of the hUTC secretome. Our results showed that hUTCs secrete factors that strongly promote neuronal survival. We found that the survival-promoting function of hUTCs is not shared by astrocytes. In agreement with this, the majority of the survival-promoting effect of hUTCs is not dependent on TSPs.

Our results demonstrate that silencing TSP2 or TSP4, but not TSP1, have minor but significant negative effects on the overall survival activity of UCM. Interestingly, supplementing the TSP $1+2+4-\mathrm{KD}$ UCM with pure TSPs did not recover the full survival effect of UCM. This result indicates that the reduction we see in the neurotrophic function of TSP-KD UCM is not due to a direct effect of TSP loss. It is possible that TSPs are involved in the secretion of the survival factors from hUTCs. In agreement with this, TSP4 is a known component of endoplasmic reticulum stress response in heart muscle that is used for the trafficking and secretion of proteins (Lynch et al., 2012).

BDNF, CNTF, and IGF-1, are known to provide neurotrophic effects on RGCs via distinct pathways. However, the activity of the neurotrophic pathways depends on the presence of forskolin in the culture media, which ensures increased c-AMP levels in RGCs (Meyer-Franke et al., 1995). Our results show that, similar to these known trophic pathways, UCM's strong effect on RGC survival also requires forskolin. Therefore, it is plausible that hUTCs secrete these factors. Indeed, several studies revealed that hUTCs make BDNF (Lund et al., 2007; Alder et al., 2012). However, testing the combinatorial effects of BDNF (or CNTF) with UCM revealed that UCM could provide additional neurotrophic effects when used together with these growth factors. This result suggests that UCM might contain additional factors that support neuronal survival.

In conclusion, using a purified neuronal culture system, here we demonstrated that hUTCs secrete factors that affect multiple aspects of neuronal function and structure. Moreover, we showed that TSP family members TSP1, TSP2, and TSP4 mediate 
the synaptogenic and neurite outgrowth-promoting functions of hUTCs. Notably, hUTCs can promote neurite outgrowth of RGCs, even in the presence of neurite growth inhibitors, CSPG, Nogo-A, or MBP, via TSP2 and TSP4. Together, these results highlight the unique neuroprotective properties of hUTCs and pinpoint the TSPs that they secrete as the molecules that potentially drive the therapeutic effects of these cells.

\section{References}

Abramov E, Dolev I, Fogel H, Ciccotosto GD, Ruff E, Slutsky I (2009) Amyloid-beta as a positive endogenous regulator of release probability at hippocampal synapses. Nat Neurosci 12:1567-1576. CrossRef Medline

Achyut BR, Varma NR, Arbab AS (2014) Application of umbilical cord blood derived stem cells in diseases of the nervous system. J Stem Cell Res Ther 4:pii1000202. CrossRef Medline

Alder J, Kramer BC, Hoskin C, Thakker-Varia S (2012) Brain-derived neurotrophic factor produced by human umbilical tissue-derived cells is required for its effect on hippocampal dendritic differentiation. Dev Neurobiol 72:755-765. CrossRef Medline

Allen NJ, Bennett ML, Foo LC, Wang GX, Chakraborty C, Smith SJ, Barres BA (2012) Astrocyte glypicans 4 and 6 promote formation of excitatory synapses via GluA1 AMPA receptors. Nature 486:410-414. CrossRef Medline

Atala A (2015) Human stem cell-derived retinal cells for macular diseases. Lancet 385:487-488. CrossRef Medline

Barres BA, Silverstein BE, Corey DP, Chun LL (1988) Immunological, morphological, and electrophysiological variation among retinal ganglion cells purified by panning. Neuron 1:791-803. CrossRef Medline

Benner EJ, Luciano D, Jo R, Abdi K, Paez-Gonzalez P, Sheng H, Warner DS, Liu C, Eroglu C, Kuo CT (2013) Protective astrogenesis from the SVZ niche after injury is controlled by Notch modulator Thbs4. Nature 497: 369-373. CrossRef Medline

Christopherson KS, Ullian EM, Stokes CC, Mullowney CE, Hell JW, Agah A, Lawler J, Mosher DF, Bornstein P, Barres BA (2005) Thrombospondins are astrocyte-secreted proteins that promote CNS synaptogenesis. Cell 120:421-433. CrossRef Medline

Conforti L, Gilley J, Coleman MP (2014) Wallerian degeneration: an emerging axon death pathway linking injury and disease. Nat Rev Neurosci 15:394-409. CrossRef Medline

Cuenca N, Pinilla I, Sauvé Y, Lund R (2005) Early changes in synaptic connectivity following progressive photoreceptor degeneration in RCS rats. Eur J Neurosci 22:1057-1072. CrossRef Medline

Davies JE, Sarkar S, Rubinsztein DC (2007) The ubiquitin proteasome system in Huntington's disease and the spinocerebellar ataxias. BMC Biochem 8 [Suppl 1]:S2.

DeFreitas MF, Yoshida CK, Frazier WA, Mendrick DL, Kypta RM, Reichardt LF (1995) Identification of integrin alpha 3 beta 1 as a neuronal thrombospondin receptor mediating neurite outgrowth. Neuron 15:333-343. CrossRef Medline

Doeppner TR, Hermann DM (2014) Stem cell-based treatments against stroke: observations from human proof-of-concept studies and considerations regarding clinical applicability. Front Cell Neurosci 8:357. CrossRef Medline

Eroglu C, Allen NJ, Susman MW, O'Rourke NA, Park CY, Ozkan E, Chakraborty C, Mulinyawe SB, Annis DS, Huberman AD, Green EM, Lawler J, Dolmetsch R, Garcia KC, Smith SJ, Luo ZD, Rosenthal A, Mosher DF, Barres BA (2009) Gabapentin receptor alpha2delta-1 is a neuronal thrombospondin receptor responsible for excitatory CNS synaptogenesis. Cell 139:380-392. CrossRef Medline

Ferreira TA, Blackman AV, Oyrer J, Jayabal S, Chung AJ, Watt AJ, Sjöström PJ, van Meyel DJ (2014) Neuronal morphometry directly from bitmap images. Nat Methods 11:982-984. CrossRef Medline

Goldberg JL, Barres BA (2000) The relationship between neuronal survival and regeneration. Annu Rev Neurosci 23:579-612. CrossRef Medline

Hynd MR, Scott HL, Dodd PR (2004) Glutamate-mediated excitotoxicity and neurodegeneration in Alzheimer's disease. Neurochem Int 45:583595. CrossRef Medline

Ippolito DM, Eroglu C (2010) Quantifying synapses: an immunocytochemistry-based assay to quantify synapse number. J Vis $\operatorname{Exp} 45$ : pii2270. CrossRef Medline

Jeong SY, Kim DH, Ha J, Jin HJ, Kwon SJ, Chang JW, Choi SJ, Oh W, Yang YS,
Kim G, Kim JS, Yoon JR, Cho DH, Jeon HB (2013) Thrombospondin-2 secreted by human umbilical cord blood-derived mesenchymal stem cells promotes chondrogenic differentiation. Stem Cells 31:2136-2148. CrossRef Medline

Jiang Q, Thiffault C, Kramer BC, Ding GL, Zhang L, Nejad-Davarani SP, Li L, Arbab AS, Lu M, Navia B, Victor SJ, Hong K, Li QJ, Wang SY, Li Y, Chopp M (2012) MRI detects brain reorganization after human umbilical tissue-derived cells (hUTCs) treatment of stroke in rat. PLoS One 7:e42845. CrossRef Medline

Jones BW, Watt CB, Frederick JM, Baehr W, Chen CK, Levine EM, Milam AH, Lavail MM, Marc RE (2003) Retinal remodeling triggered by photoreceptor degenerations. J Comp Neurol 464:1-16. CrossRef Medline

Kim DS, Li KW, Boroujerdi A, Peter Yu Y, Zhou CY, Deng P, Park J, Zhang X, Lee J, Corpe M, Sharp K, Steward O, Eroglu C, Barres B, Zaucke F, Xu ZC, Luo ZD (2012) Thrombospondin-4 contributes to spinal sensitization and neuropathic pain states. J Neurosci 32:8977-8987. CrossRef Medline

Kucukdereli H, Allen NJ, Lee AT, Feng A, Ozlu MI, Conatser LM, Chakraborty C, Workman G, Weaver M, Sage EH, Barres BA, Eroglu C (2011) Control of excitatory CNS synaptogenesis by astrocyte-secreted proteins Hevin and SPARC. Proc Natl Acad Sci U S A 108:E440-E449. CrossRef Medline

Lee HJ, Lee JK, Lee H, Shin JW, Carter JE, Sakamoto T, Jin HK, Bae JS (2010) The therapeutic potential of human umbilical cord blood-derived mesenchymal stem cells in Alzheimer's disease. Neurosci Lett 481:30-35. CrossRef Medline

Lee HJ, Lee JK, Lee H, Carter JE, Chang JW, Oh W, Yang YS, Suh JG, Lee BH, Jin HK, Bae JS (2012) Human umbilical cord blood-derived mesenchymal stem cells improve neuropathology and cognitive impairment in an Alzheimer's disease mouse model through modulation of neuroinflammation. Neurobiol Aging 33:588-602. CrossRef Medline

Liauw J, Hoang S, Choi M, Eroglu C, Choi M,Sun GH, Percy M, WildmanTobriner B, Bliss T, Guzman RG, Barres BA, Steinberg GK (2008) Thrombospondins 1 and 2 are necessary for synaptic plasticity and functional recovery after stroke. J Cereb Blood Flow Metab 28:1722-1732. CrossRef Medline

Lindvall O, Kokaia Z (2010) Stem cells in human neurodegenerative disorders: time for clinical translation? J Clin Invest 120:29-40. CrossRef Medline

Liu MC, Akle V, Zheng W, Kitlen J, O'Steen B, Larner SF, Dave JR, Tortella FC, Hayes RL, Wang KK (2006) Extensive degradation of myelin basic protein isoforms by calpain following traumatic brain injury. J Neurochem 98:700-712. CrossRef Medline

Luk KC, Kehm V, Carroll J, Zhang B, O'Brien P, Trojanowski JQ, Lee VM (2012) Pathological alpha-synuclein transmission initiates Parkinsonlike neurodegeneration in nontransgenic mice. Science 338:949-953. CrossRef Medline

Lund RD, Wang S, Lu B, Girman S, Holmes T, Sauvé Y, Messina DJ, Harris IR, Kihm AJ, Harmon AM, Chin FY, Gosiewska A, Mistry SK (2007) Cells isolated from umbilical cord tissue rescue photoreceptors and visual functions in a rodent model of retinal disease. Stem Cells 25:602-611. CrossRef Medline

Lynch JM, Maillet M, Vanhoutte D, Schloemer A, Sargent MA, Blair NS, Lynch KA, Okada T, Aronow BJ, Osinska H, Prywes R, Lorenz JN, Mori K, Lawler J, Robbins J, Molkentin JD (2012) A thrombospondindependent pathway for a protective ER stress response. Cell 149:12571268. CrossRef Medline

Mauch DH, Nägler K, Schumacher S, Göritz C, Müller EC, Otto A, Pfrieger FW (2001) CNS synaptogenesis promoted by glia-derived cholesterol. Science 294:1354-1357. CrossRef Medline

McCarthy KD, de Vellis J (1980) Preparation of separate astroglial and oligodendroglial cell cultures from rat cerebral tissue. J Cell Biol 85:890-902. CrossRef Medline

McKinstry SU, Karadeniz YB, Worthington AK, Hayrapetyan VY, Ozlu MI, Serafin-Molina K, Risher WC, Ustunkaya T, Dragatsis I, Zeitlin S, Yin $\mathrm{HH}$, Eroglu C (2014) Huntingtin is required for normal excitatory synapse development in cortical and striatal circuits. J Neurosci 34:94559472. CrossRef Medline

Meyer-Franke A, Kaplan MR, Pfrieger FW, Barres BA (1995) Characterization of the signaling interactions that promote the survival and growth of developing retinal ganglion cells in culture. Neuron 15:805-819. CrossRef Medline

Milnerwood AJ, Raymond LA (2010) Early synaptic pathophysiology in 
neurodegeneration: insights from Huntington's disease. Trends Neurosci 33:513-523. CrossRef Medline

Moore TL, Pessina MA, Finklestein SP, Kramer BC, Killiany RJ, Rosene DL (2013) Recovery of fine motor performance after ischemic damage to motor cortex is facilitated by cell therapy in the rhesus monkey. Somatosens Mot Res 30:185-196. CrossRef Medline

Neugebauer KM, Emmett CJ, Venstrom KA, Reichardt LF (1991) Vitronectin and thrombospondin promote retinal neurite outgrowth: developmental regulation and role of integrins. Neuron 6:345-358. CrossRef Medline

Neukomm LJ, Freeman MR (2014) Diverse cellular and molecular modes of axon degeneration. Trends Cell Biol 24:515-523. CrossRef Medline

Niederöst B, Oertle T, Fritsche J, McKinney RA, Bandtlow CE (2002) Nogo-A and myelin-associated glycoprotein mediate neurite growth inhibition by antagonistic regulation of RhoA and Rac1. J Neurosci 22: 10368-10376. Medline

Oganesian A, Armstrong LC, Migliorini MM, Strickland DK, Bornstein P (2008) Thrombospondins use the VLDL receptor and a nonapoptotic pathway to inhibit cell division in microvascular endothelial cells. Mol Biol Cell 19:563-571. CrossRef Medline

Orth M, Schippling S, Schneider SA, Bhatia KP, Talelli P, Tabrizi SJ, Rothwell JC (2010) Abnormal motor cortex plasticity in premanifest and very early manifest Huntington disease. J Neurol Neurosurg Psychiatry 81: 267-270. CrossRef Medline

Park SI, Lim JY, Jeong CH, Kim SM, Jun JA, Jeun SS, Oh WI (2012) Human umbilical cord blood-derived mesenchymal stem cell therapy promotes functional recovery of contused rat spinal cord through enhancement of endogenous cell proliferation and oligogenesis. J Biomed Biotechnol 2012:362473. CrossRef Medline

Pfrieger FW, Barres BA (1997) Synaptic efficacy enhanced by glial cells in vitro. Science 277:1684-1687. CrossRef Medline

Plowey ED, Chu CT (2011) Synaptic dysfunction in genetic models of Parkinson's disease: a role for autophagy? Neurobiol Dis 43:60-67. CrossRef Medline

Popovich PG (2012) Building bridges for spinal cord repair. Cell 150:11051106. CrossRef Medline

Raff MC, Whitmore AV, Finn JT (2002) Axonal self-destruction and neurodegeneration. Science 296:868-871. CrossRef Medline

Rao MS, Mattson MP (2001) Stem cells and aging: expanding the possibilities. Mech Ageing Dev 122:713-734. CrossRef Medline

Reiner A, Albin RL, Anderson KD, D'Amato CJ, Penney JB, Young AB (1988) Differential loss of striatal projection neurons in Huntington disease. Proc Natl Acad Sci U S A 85:5733-5737. CrossRef Medline

Risher WC, Eroglu C (2012) Thrombospondins as key regulators of synap- togenesis in the central nervous system. Matrix Biol 31:170-177. CrossRef Medline

Rowe DD, Leonardo CC, Recio JA, Collier LA, Willing AE, Pennypacker KR (2012) Human umbilical cord blood cells protect oligodendrocytes from brain ischemia through Akt signal transduction. J Biol Chem 287:41774187. CrossRef Medline

Silver J, Miller JH (2004) Regeneration beyond the glial scar. Nat Rev Neurosci 5:146-156. CrossRef Medline

Stapulionis R, Oliveira CL, Gjelstrup MC, Pedersen JS, Hokland ME, Hoffmann SV, Poulsen K, Jacobsen C, Vorup-Jensen T (2008) Structural insight into the function of myelin basic protein as a ligand for integrin alpha M beta 2. J Immunol 180:3946-3956. CrossRef Medline

Tso MO, Zhang C, Abler AS, Chang CJ, Wong F, Chang GQ, Lam TT (1994) Apoptosis leads to photoreceptor degeneration in inherited retinal dystrophy of RCS rats. Invest Ophthalmol Vis Sci 35:2693-2699. Medline

Ullian EM, Sapperstein SK, Christopherson KS, Barres BA (2001) Control of synapse number by glia. Science 291:657-661. CrossRef Medline

Usher LC, Johnstone A, Ertürk A, Hu Y, Strikis D, Wanner IB, Moorman S, Lee JW, Min J, Ha HH, Duan Y, Hoffman S, Goldberg JL, Bradke F, Chang YT, Lemmon VP, Bixby JL (2010) A chemical screen identifies novel compounds that overcome glial-mediated inhibition of neuronal regeneration. J Neurosci 30:4693-4706. CrossRef Medline

Walker BA, Ji SJ, Jaffrey SR (2012) Intra-axonal translation of RhoA promotes axon growth inhibition by CSPG. J Neurosci 32:14442-14447. CrossRef Medline

Winzeler A, Wang JT (2013) Purification and culture of retinal ganglion cells from rodents. Cold Spring Harb Protoc 2013:643-652. CrossRef Medline

Zhang J, Sun X, Zheng S, Liu X, Jin J, Ren Y, Luo J (2014) Myelin basic protein induces neuron-specific toxicity by directly damaging the neuronal plasma membrane. PLoS One 9:e108646. CrossRef Medline

Zhang L, Li Y, Zhang C, Chopp M, Gosiewska A, Hong K (2011) Delayed administration of human umbilical tissue-derived cells improved neurological functional recovery in a rodent model of focal ischemia. Stroke 42:1437-1444. CrossRef Medline

Zhang L, Li Y, Romanko M, Kramer BC, Gosiewska A, Chopp M, Hong K (2012) Different routes of administration of human umbilical tissuederived cells improve functional recovery in the rat after focal cerebral ischemia. Brain Res 1489:104-112. CrossRef Medline

Zhang L, Yi L, Chopp M, Kramer BC, Romanko M, Gosiewska A, Hong K (2013) Intravenous administration of human umbilical tissue-derived cells improves neurological function in aged rats after embolic stroke. Cell Transplant 22:1569-1576. CrossRef Medline 